Cochrane Database of Systematic Reviews

\title{
Alemtuzumab for multiple sclerosis (Review)
}

Riera R, Porfírio GJM, Torloni MR

Riera R, Porfírio GJM, Torloni MR.

Alemtuzumab for multiple sclerosis.

Cochrane Database of Systematic Reviews 2016, Issue 4. Art. No.: CD011203.

DOI: 10.1002/14651858.CD011203.pub2.

www.cochranelibrary.com 
TABLE OF CONTENTS

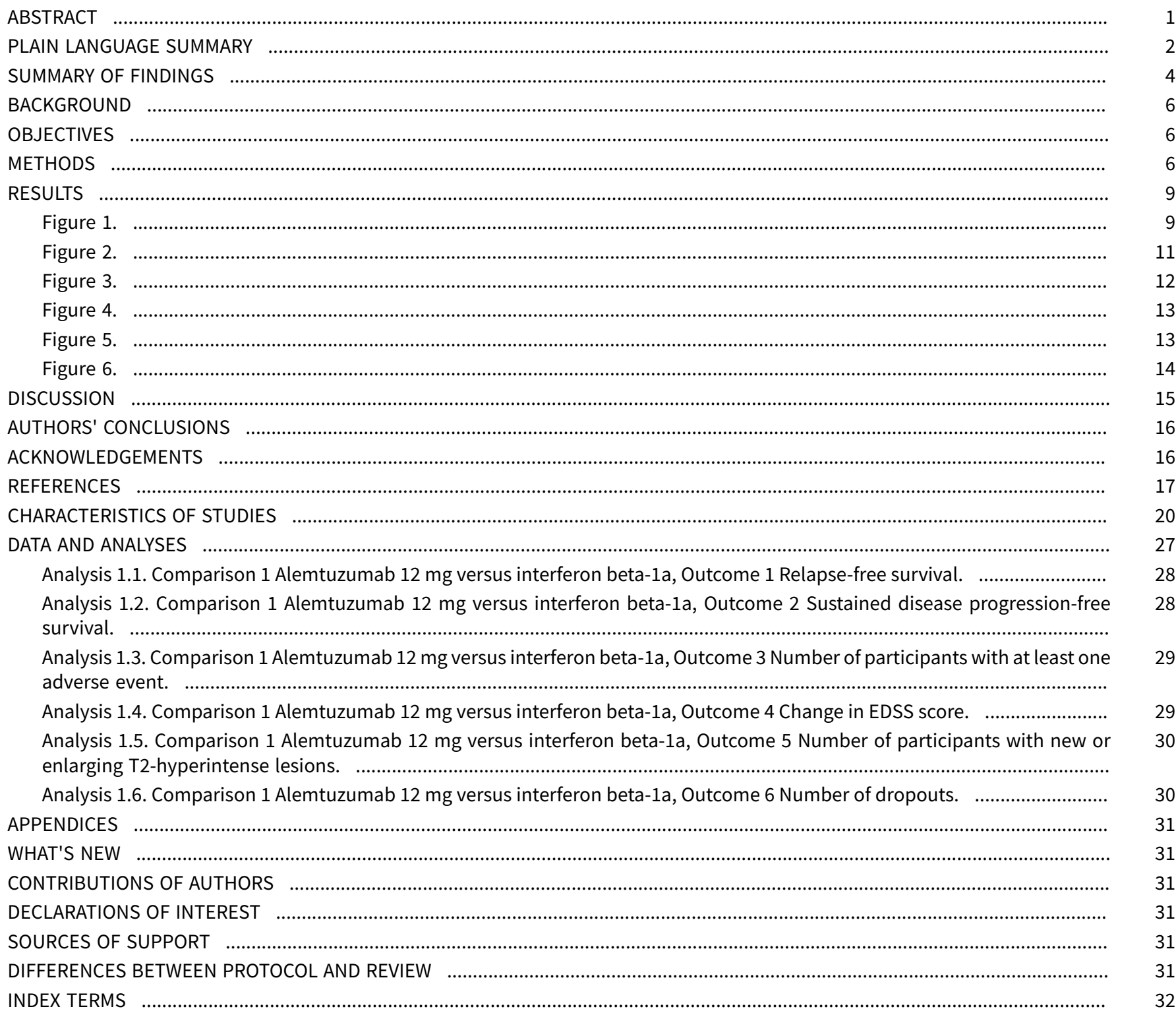


[Intervention Review]

\section{Alemtuzumab for multiple sclerosis}

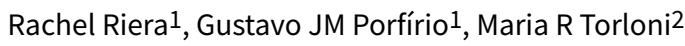

${ }^{1}$ Centro de Estudos em Medicina Baseada em Evidências e Avaliação Tecnológica em Saúde, Brazilian Cochrane Centre, São Paulo, Brazil. 2Brazilian Cochrane Centre, Centro de Estudos de Saúde Baseada em Evidências e Avaliação Tecnológica em Saúde, São Paulo, Brazil

Contact: Rachel Riera, Centro de Estudos em Medicina Baseada em Evidências e Avaliação Tecnológica em Saúde, Brazilian Cochrane Centre, Rua Borges Lagoa, 564 cj 63, São Paulo, SP, 04038-000, Brazil. rachelriera@hotmail.com.

Editorial group: Cochrane Multiple Sclerosis and Rare Diseases of the CNS Group.

Publication status and date: New, published in Issue 4, 2016.

Citation: Riera R, Porfírio GJM, Torloni MR. Alemtuzumab for multiple sclerosis. Cochrane Database of Systematic Reviews 2016 , Issue 4. Art. No.: CD011203. DOI: 10.1002/14651858.CD011203.pub2.

Copyright @ 2016 The Cochrane Collaboration. Published by John Wiley \& Sons, Ltd.

\section{A B S T R A C T}

\section{Background}

Multiple sclerosis (MS) is an autoimmune, T-cell-dependent, inflammatory, demyelinating disease of the central nervous system, with an unpredictable course. Current MS therapies focus on treating exacerbations, preventing new exacerbations and avoiding the progression of disability. However, at present there is no effective treatment that is capable of safely and effectively reaching these objectives. This has led to the development and investigation of new drugs. Recent clinical trials suggest that alemtuzumab, a humanised monoclonal antibody against cell surface CD52, could be a promising option for MS.

\section{Objectives}

To assess the safety and effectiveness of alemtuzumab used alone or associated with other treatments to decrease disease activity in patients with any form of MS.

\section{Search methods}

We searched the Trials Register of the Cochrane Multiple Sclerosis and Rare Diseases of the CNS Group (30 April 2015), which contains trials from the Cochrane Central Register of Controlled Trials (CENTRAL), MEDLINE, EMBASE, CINAHL, LILACS and the trial registry databases ClinicalTrials.gov and WHO International Clinical Trials Registry Platform. There was no restriction on the source, publication date or language.

\section{Selection criteria}

All randomised clinical trials (RCTs) involving adults diagnosed with any form of MS according to the McDonald criteria, comparing alemtuzumab alone or associated with other medications, at any dose and for any duration, versus placebo or any other active drug therapy or alemtuzumab in other dose, regimen or duration. The co-primary outcomes were relapse-free survival, sustained disease progression and number of participants with at least one of any adverse events, including serious adverse events.

\section{Data collection and analysis}

Two independent review authors performed study selection, data extraction and 'Risk of bias' assessment. A third review author checked the process for accuracy. We used the Cochrane 'Risk of bias' tool to assess the risk of bias of the studies included in the review. We used the GRADE system to assess the quality of the body of evidence. To measure the treatment effect on dichotomous outcomes we used the risk ratio (RR); for the treatment effect on continuous outcomes, we used the mean difference (MD) and for time-to-event outcomes we used hazard ratio (HR). We calculated $95 \%$ confidence intervals $(\mathrm{Cl})$ for these measures. When there was no heterogeneity, we used a fixedeffect model to pool data. 


\section{Main results}

Three RCTs (1713 participants) fulfilled the selection criteria and we included them in the review. All three trials compared alemtuzumab versus subcutaneous interferon beta-1a for patients with relapsing-remitting MS. Patients were treatment-naive in the CARE-MS and CAMMS223 studies. The CARE-MS II study included patients with at least one relapse while being treated with interferon beta or glatiramer acetate. Alemtuzumab was given for 12 or 24 months; for some outcomes, the follow-up period reached 36 months. The regimens were (a) $12 \mathrm{mg}$ or $24 \mathrm{mg}$ per day administered intravenously, once a day for five consecutive days at month 0 and 12 or (b) 24 mg per day, intravenously, once a day for three consecutive days at month 12 and 24 . The patients in the other arm of the trials received interferon beta-1a $44 \mu \mathrm{g}$ subcutaneously three times weekly after dose titration.

At 24 months, alemtuzumab $12 \mathrm{mg}$ was associated with: (a) higher relapse-free survival (hazard ratio (HR) $0.50,95 \% \mathrm{Cl} 0.41$ to 0.60 ; 1248 participants, two studies, moderate quality evidence); (b) higher sustained disease progression-free survival ( $\mathrm{HR} 0.62,95 \% \mathrm{Cl} 0.44$ to 0.87 ; 1191 participants; two studies; moderate quality evidence); (c) a slightly higher number of participants with at least one adverse event (RR $1.04,95 \% \mathrm{Cl} 1.01$ to 1.06 ; 1248 participants; two studies; moderate quality evidence); (d) a lower number of participants with new or enlarging T2-hyperintense lesions on magnetic resonance imaging (MRI) (RR 0.74, 95\% Cl 0.59 to $0.91 ; 1238$ participants; two studies; I $^{2}=$ $80 \%$ ); and (e) a lower number of dropouts (RR $0.31,95 \% \mathrm{Cl} 0.23$ to $0.41 ; 1248$ participants; two studies, $\mathrm{I}^{2}=29 \%$; low quality evidence).

At 36 months, alemtuzumab $24 \mathrm{mg}$ was associated with: (a) higher relapse-free survival (45 versus 17 ; $\mathrm{HR} 0.21,95 \% \mathrm{Cl} 0.11$ to 0.40 ; one study; 221 participants); (b) a higher sustained disease progression-free survival ( $\mathrm{HR} 0.33,95 \% \mathrm{Cl} 0.16$ to 0.69 ; one study; 221 participants); and (c) no statistical difference in the rate of participants with at least one adverse event. We did not find any study that reported any of the following outcomes: rate of participants free of clinical disease activity, quality of life, fatigue or change in the numbers of MRI T2- and T1-weighted lesions after treatment. It was not possible to perform subgroup analyses according to disease type and disability at baseline due to lack of data.

\section{Authors' conclusions}

In patients with relapsing-remitting MS, alemtuzumab $12 \mathrm{mg}$ was better than subcutaneous interferon beta-1a for the following outcomes assessed at 24 months: relapse-free survival, sustained disease progression-free survival, number of participants with at least one adverse event and number of participants with new or enlarging T2-hyperintense lesions on MRI. The quality of the evidence for these results was low to moderate. Alemtuzumab $24 \mathrm{mg}$ seemed to be better than subcutaneous interferon beta-1a for relapse-free survival and sustained disease progression-free survival, at 36 months.

More randomised clinical trials are needed to evaluate the effects of alemtuzumab on other forms of MS and compared with other therapeutic options. These new studies should assess additional relevant outcomes such as the rate of participants free of clinical disease activity, quality of life, fatigue and adverse events (individual rates, serious adverse events and long-term adverse events). Moreover, these new studies should evaluate other doses and durations of alemtuzumab course.

\section{PLAIN LANGUAGE SUMMARY}

\section{Alemtuzumab for multiple sclerosis}

\section{Background}

Multiple sclerosis (MS) is a chronic disease of the nervous system that affects young and middle-aged adults. Repeated damage to the myelin sheaths (the membranes that cover and protect nerves) and other parts of the nerves can lead to serious disability. MS may be related to problems in the immune system. Alemtuzumab is a biologic drug (a type of antibody), which has already been used for other diseases.

\section{Study characteristics}

We found three studies (including 1713 participants) that fulfilled the review selection criteria. All studies compared alemtuzumab versus subcutaneous interferon beta-1a for people with relapsing-remitting MS. In two of the studies (CARE-MS and CAMMS223) the participants were being treated for the first time (treatment-naive). The third study (CARE-MS II) included participants with at least one relapse while being treated with interferon beta or glatiramer acetate for at least six months.

\section{Key results}

The review of these comparative studies found that, compared to subcutaneous interferon beta-1a, alemtuzumab reduces the risk of relapse, improves function and seems not to increase the overall risk of adverse events. Additionally, alemtuzumab reduces the risk of new or enlarging lesions of MS detected using magnetic resonance imaging (MRI). However, there is a lack of information about the effects of alemtuzumab on several patient-related outcomes such as (a) quality of life, (b) the rate of each adverse events (separately) and (c) the frequency of long-term adverse events and serious adverse events.

\section{Quality of the evidence}


The overall methodological quality of the included studies was moderate to high. However, because of the small number of included studies and the low rate of events, we judged the overall quality of the evidence for the main outcomes as very low to moderate. This means that new studies are likely to have an important impact on our confidence in the estimate of effect and may change the estimate or that we are very uncertain about the estimate. 
SUMMARY OF FINDINGS

Summary of findings for the main comparison. Alemtuzumab $12 \mathrm{mg}$ compared to interferon beta-1a for multiple sclerosis

Alemtuzumab $12 \mathrm{mg}$ compared to interferon beta-1a for multiple sclerosis

Patient or population: patients with multiple sclerosis

Settings: outpatients

Intervention: alemtuzumab $12 \mathrm{mg}$

Comparison: interferon beta- $1 \mathrm{a}$

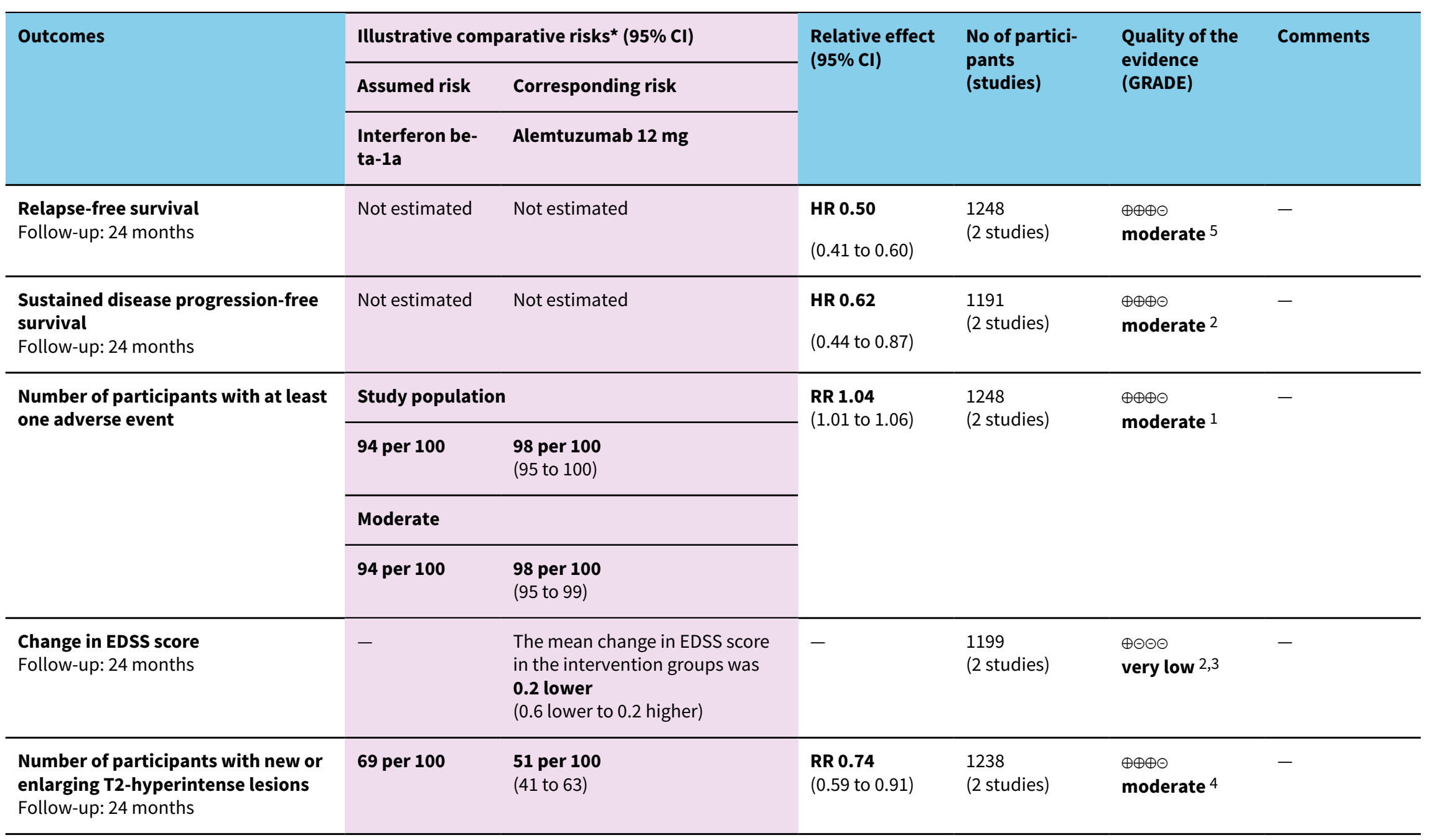




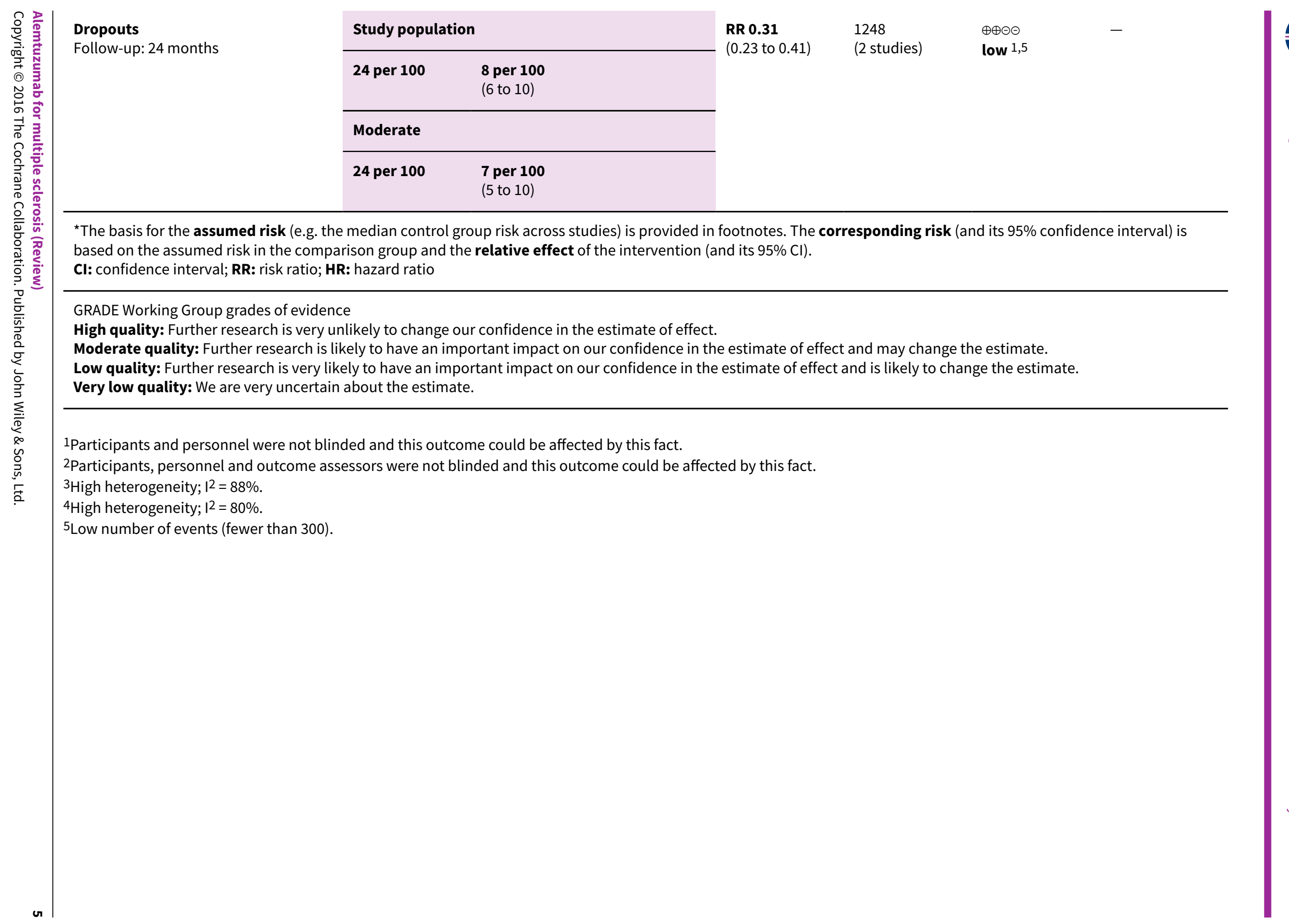




\section{B A C K G R O U N D}

\section{Description of the condition}

Multiple sclerosis (MS) is an autoimmune, inflammatory, demyelinating disease of the central nervous system (brain and spinal cord), the causes of which remain unknown (Coles 1999a; Gray 2004). It is the most common cause of non-traumatic neurological disability in young adults (Noseworthy 2000). Almost two million people in the world are affected by this condition, which can substantially impair patients' quality of life and is associated with high costs for patients, their families and society in general (Multiple Sclerosis International Federation 2010).

Four types of MS have been identified: relapsing-remitting (RR), secondary-progressive (SP), primary-progressive (PP) and progressive-relapsing (PR). The disease course is unpredictable; while some individuals are minimally affected, others show rapid progression of the disease, reaching total physical incapacity (Lublin 1996). In the first form, MS is characterised by relapses and remissions (RR), but given time sequelae from relapses may cause increased disability (Hawkins 1999). In some patients, the disease is progressive from its onset (PP); others experience periods of progression followed by relapses and remissions (SP) (Lublin 1996). In other cases, MS shows progression from onset but with clear relapses (PR).

\section{Description of the intervention}

Therapeutic strategies for MS aim to treat exacerbations, prevent new exacerbations and avoid progression of disability (Filippini 2013). Current disease-modifying treatments decrease the frequency of relapse and modestly reduce the accumulation of disability (Coles 2006; Rieckmann 2009). Consequently, new agents that effectively control the disease are needed.

Alemtuzumab (Lemtrada, previously known as Campath-1H) is a humanised monoclonal antibody against cell surface CD52, which can be found in a variety of cell populations, including $\mathrm{B}$ and $\mathrm{T}$ lymphocytes, thymocytes and monocytes but not in haematological precursors or plasma cells (Gilleece 1993). However, the exact function of CD52 is still unknown (Xia 1991).

In 2001, alemtuzumab was approved for fludarabine-resistant Bcell chronic lymphocytic leukaemia (FDA 2001; Keating 2002). Since that time, it has been used for several other diseases (licensed or off-label use), including immune thrombocytopenic purpura, aplastic anaemia, autoimmune haemolytic anaemia, vasculitis, hematopoietic stem cell transplants (as a conditioning regimen) and organ transplants (as an induction agent) (Gomez-Almaguer 2012; Lockwood 2003; Waldmann 2005; Weissenbacher 2010).

A study published in 1999, including 36 participants with progressive MS, reported that daily intravenous infusions of alemtuzumab (20 mg over four hours for five days) were associated with a reduction in gadolinium-enhanced magnetic resonance imaging (MRI) lesions and a reduction in relapses, with no clinical improvement in disability (Coles 1999b). Open studies involving participants with relapsing-remitting MS reported that the drug reduced relapse rates and disability (Coles 2006; Hirst 2008).

Alemtuzumab is already approved for MS in the European Union (EMA 2013). The US Food and Drug Administration (FDA) approved alemtuzumab for the treatment of people with RR MS who have had an inadequate response to two or more drugs indicated for the treatment of MS (FDA 2014).

The guidelines from the Association of British Neurologists identified alemtuzumab as having greatest activity in preventing relapses. However, because of safety concerns, the guidelines recommended this drug as a second-line treatment, or for patients with the rapidly evolving RR form (Scolding 2015).

Alemtuzumab is available for the treatment of MS in $12 \mathrm{mg} / 1.2$ $\mathrm{mL}$ single-dose vials $(10 \mathrm{mg} / \mathrm{mL})$. The proposed initial dosage for MS is $12 \mathrm{mg}$ daily for five consecutive days (intravenous infusion), followed by a second treatment course of $12 \mathrm{mg}$ /daily for three consecutive days. The second treatment course is administered 12 months after the first course. Premedication with corticosteroids is recommended immediately before alemtuzumab and during the first three days of any treatment course (FDA 2014). The overall halflife of the drug is approximately 21 days. Alemtuzumab is available as a liquid to be made up into a solution for infusion (drip) into a vein. An infusion provides $12 \mathrm{mg}$ and lasts around four hours.

Alemtuzumab can produce serious adverse events including other autoimmune syndromes affecting the thyroid and blood cells (thrombocytopenia, haemolytic anaemia, pancytopenia) and nephropathies, and it can increase the risk of thyroid cancer (FDA 2014). At five-year follow-up, the cumulative risk of autoimmune disease is approximately $22 \%$, Graves' disease $12 \%$, immune thrombocythaemia purpura 3\% and Goodpasture's disease (severe glomerulopathy) $0.4 \%$ (Cossburn 2011).

Recently, the FDA updated a general overview of recommendations (Risk Evaluation and Mitigation Strategy Program) about Lemtrada for patients, pharmacies and healthcare providers (FDA 2015).

\section{How the intervention might work}

Previous researches have suggested that alemtuzumab depletes the $\mathrm{T}$ - and B-cells that may be responsible for cellular damage, while sparing innate immune cells (Rao 2012). Change in the composition of lymphocytes that accompanies lymphocyte reconstitution has also been reported (Hill-Cawthorne 2012).

\section{Why it is important to do this review}

Results of randomised controlled trials (RCTs) of alemtuzumab for MS are promising and a systematic review of all RCTs was warranted to evaluate its effectiveness and safety for MS.

\section{OB JECTIVES}

To assess the safety and effectiveness of alemtuzumab used alone or associated with other treatments to decrease disease activity in people with any form of MS.

\section{METHODS}

\section{Criteria for considering studies for this review}

\section{Types of studies}

We included randomised, double-blind clinical trials (RCTs). We did not consider cross-over trials. 


\section{Types of participants}

We included adults diagnosed with MS according to the McDonald criteria (McDonald 2001; Polman 2011), or Poser criteria (Poser 1983). We considered participants with any form of MS (relapsing-remitting, primary-progressive, secondary-progressive or progressive-relapsing) for inclusion.

\section{Types of interventions}

- Experimental intervention: alemtuzumab alone or associated with other medications at any dose and for any course duration.

- Comparator: placebo, any other active drug therapy (i.e. corticosteroids, plasmapheresis, beta interferons, glatiramer acetate, fingolimod, natalizumab, mitoxantrone, teriflunomide or dimethyl fumarate).

\section{Types of outcome measures}

\section{Primary outcomes}

- Relapse-free survival. Relapse was defined as newly developed or recently worsened symptoms of neurological dysfunction, lasting longer than 24 hours and objectively confirmed. However, we considered less stringent criteria and assessed these separately.

- Sustained disease progression-free survival, defined as a $\geq 1.0$ point increase in the Expanded Disability Status Scale (EDSS) score (Kurtzke 1983) for participants with a baseline score $\leq 5.0$ or $\mathrm{a} \geq 0.5$-point increase for participants with a baseline score $\geq$ 5.5 points confirmed at six months. We considered a one-point increase in EDSS score confirmed at three months' follow-up as a surrogate outcome measure of progression.

- Number of participants with at least one adverse event, including serious adverse events.

All primary outcomes were assessed after 12 and 24 months followup and at the end of the follow-up period.

\section{Secondary outcomes}

- Number of participants free of clinical disease activity, defined as no relapses and no sustained accumulation of disability. Sustained accumulation disability was defined as an increase of at least 1.5 points on the Expanded Disability Status Scale (EDSS) for patients with a baseline score of 0 and of at least 1.0 point for patients with a baseline score of 1.0 or more.

- Quality of life as assessed by the Multiple Sclerosis Quality of Life scale (MSQOL)-54 (Vickrey 1995) or the Multiple Sclerosis Quality of Life Inventory (MSQLI) (Fischer 1999).

- Change in disability as assessed by the EDSS (Kurtzke 1983).

- Fatigue as assessed by the Fatigue Severity Scale or the Fatigue Index Scale (Krupp 1989).

- Number of participants with new or enlarging T2-hyperintense lesions on magnetic resonance imaging (Li 1999).

- Number of participants who dropped out.

All secondary outcomes would be assessed after 12 and 24 months and at the end of the follow-up period.

\section{Search methods for identification of studies}

We conducted a systematic search without language restrictions to identify all relevant published randomised controlled trials using the optimally sensitive strategy developed by Cochrane for the identification of RCTs.

\section{Electronic searches}

The Trials Search Co-ordinator searched the Trials Register of the Cochrane Multiple Sclerosis and Rare Diseases of the CNS Group (30 April 2015) which, among other sources, includes trials from:

- Cochrane Central Register of Controlled Trials (CENTRAL 2015, Issue 4);

- MEDLINE (PubMed) (1966 to 30 April 2015);

- EMBASE (Embase.com) (1974 to 30 April 2015);

- Cumulative Index to Nursing and Allied Health Literature (CINAHL) (EBSCO host) (1981 to 30 April 2015);

- Latin American and Caribbean Health Science Information Database (LILACS) (Bireme) (1982 to 30 April 2015);

- ClinicalTrials.gov (www.clinicaltrials.gov);

- World Health Organization (WHO) International Clinical Trials Registry Platform (apps.who.int/trialsearch).

Information on the Trials Register of the Review Group and details of search strategies used to identify trials can be found in the 'Specialised Register' section within the Cochrane Multiple Sclerosis and Rare Diseases of the CNS Group module.

The keywords used to search for trials for this review are listed in Appendix 1.

\section{Searching other resources}

In addition, we used the following methods.

- We screened the bibliographic references of identified studies to identify additional studies.

- We contacted pharmaceutical companies (Genzyme-Sanofi and Bayer) for information on any unpublished trials.

- We contacted the main authors of studies if data reported in the original articles were incomplete and we asked experts in this field about additional unpublished or ongoing studies.

\section{Data collection and analysis}

\section{Selection of studies}

Two review authors (RR and GJMP) independently screened the titles and abstracts of all records retrieved by the search in order to identify potentially relevant studies. We retrieved the full-text reports/publications of those deemed eligible for inclusion and three review authors (RR, GP and MRT) independently read the full texts to identify studies that met the selection criteria. The review authors recorded the reasons for exclusion of rejected studies. Disagreements between two review authors (RR and GJMP) were discussed until a consensus was reached with the consultation of a third review author (MRT) if needed.

\section{Data extraction and management}

We used a data collection form to report information on study characteristics and outcome data. Three review authors (RR, GP and MRT) extracted the following information from the primary studies included in the review.

- Publication details (i.e. year, country, authors). 
- Study design and methods: inclusion/exclusion criteria, randomisation method, allocation concealment, blinding.

- Setting.

- Population data (i.e. age, severity of disease, type of MS).

- Details of intervention (i.e. dose, regimen, duration).

- Outcome measures (including effectiveness and adverse effects).

- Number of dropouts.

- Length of follow-up.

- Types of data analyses (e.g. intention-to-treat, modified intention-to-treat).

- Any other potential risk of bias.

We discussed disagreements until consensus was reached, with the involvement of a third review author (MRT) if needed. One review author (RR) inserted data into the Review Manager 5.3 software (RevMan 2015). We double-checked that data were entered correctly into the form.

\section{Assessment of risk of bias in included studies}

Three review authors (RR, GJMP and MRT) independently assessed the methodological quality of included clinical trials using the criteria outlined in the Cochrane Handbook for Systematic Reviews of Interventions (Higgins 2011). We assessed the risk of bias according to the following domains.

- Sequence generation: Was the allocation sequence adequately generated?

- Allocation concealment: Was allocation adequately concealed?

- Blinding of participants, personnel and outcome assessors: Was knowledge of the allocated interventions adequately prevented during the study?

- Incomplete outcome data: Were outcome data adequately assessed and accounted for? (We considered a loss to follow-up rate greater than $15 \%$ as high risk).

- Selective outcome reporting: Were the reports of the study free of any suggestion of selective outcome reporting?

- Other potential threats to validity: Was the study apparently free from other problems that could put it at risk of bias?

We graded each potential source of bias as high, low or unclear and provided a quote from the study report together with a justification for our judgement in the 'Risk of bias' table.

We considered the overall quality of the studies good if the sequence generation, allocation concealment and blinding (patients and personnel, and assessors) domains were all at low risk of bias. We considered the overall quality of the studies moderate if one of these domains was categorised as being at unclear risk. Finally, we considered the overall quality high if at least one of these domains was categorised as high risk of bias.

\section{Measures of treatment effect}

For each outcome, we calculated a summarised estimate of treatment effect (with 95\% confidence interval (CI)) for each comparison. We reported dichotomous outcomes as risk ratios (RRs). We used the mean difference (MD) for continuous outcomes and the hazard ratio (HR) for time-to-event outcomes.

\section{Unit of analysis issues}

The unit of analysis was the individual participant.

\section{Dealing with missing data}

In cases where there were missing or unavailable data, we contacted the primary authors for further information. We performed a search for protocols or additional articles related to the included trials (or both). If relevant data were unavailable, we presented and discuss the results in the main text of the review.

\section{Assessment of heterogeneity}

We investigated heterogeneity using the $\mathrm{Chi}^{2}$ test and the $\mathrm{I}^{2}$ statistic, which indicates the degree of variation across studies that is due to heterogeneity rather than due to chance. We considered an $1^{2}$ value greater than $50 \%$ as substantial heterogeneity (Higgins 2011). We checked clinical and methodological differences as potential causes of heterogeneity.

\section{Assessment of reporting biases}

As it was not possible to pool more than 10 studies, we did not use funnel plots to explore possible publication bias.

\section{Data synthesis}

We summarised data using the Review Manager 5 software (RevMan 2015). When significant methodological or clinical heterogeneity existed,we used a random-effects model; otherwise we used a fixed-effect model.

\section{Subgroup analysis and investigation of heterogeneity}

We planned the following subgroup analyses:

- Treatment duration (12 or 24 months).

- Different doses and regimens of alemtuzumab (12 mg or $24 \mathrm{mg}$ ).

- Disease type: relapsing-remitting, primary-progressive, secondary-progressive or progressive-relapsing.

- Disability at baseline (EDSS score $\leq 5.0$ or $\geq 5.5$ ).

- Naive or previously treated participants.

However, we did not carry out subgroup analyses to consider disease type and disability at baseline due to lack of available data.

\section{Sensitivity analysis}

We planned to perform sensitivity analysis by excluding trials of low or moderate quality (or both) and comparing the results with the overall findings. However, since we included only three trials in the review, we deemed this analysis inappropriate.

\section{'Summary of findings' table}

We created a 'Summary of findings' table (Summary of findings for the main comparison) by using the following outcomes:

- Relapse-free survival.

- Sustained disease progression-free survival.

- Number of participants with at least one adverse event, including serious adverse events.

- Change in disability assessed by the EDSS.

- Number of participants with new or enlarging T2-hyperintense lesions. 
- Number of participants who dropped out.

We used the five GRADE parameters (risk of bias, inconsistency, imprecision, indirectness and publication bias) to assess the quality of the body of evidence as it relates to the studies that contributed data to the meta-analyses for prespecified outcomes. We used the methods and recommendations described in Section 8.5 and Chapter 12 of the Cochrane Handbook for Systematic Reviews of Interventions (Higgins 2011) using the GRADEpro software (GRADEpro 2008). We justified all decisions to downgrade or upgrade the quality of studies in the footnotes and we made comments to aid readers' understanding of the review when necessary.

Figure 1. Study flow diagram.

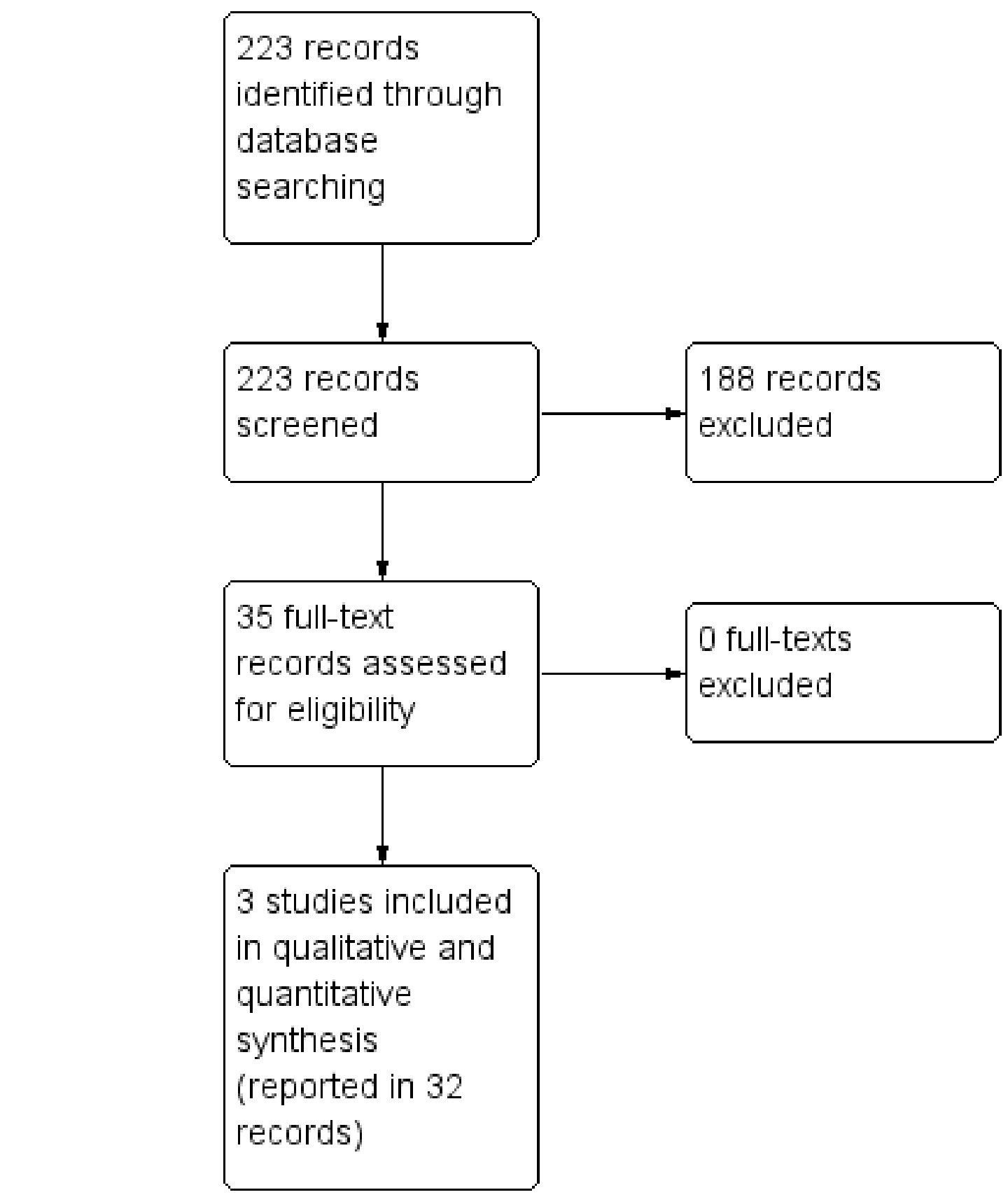

RESULTS

\section{Description of studies}

Results of the search

The search strategy retrieved 223 references: two in CENTRAL, 128 in MEDLINE, 82 in EMBASE, three in CINAHL, none in PEDro, none in LILACS, four in ClinicalTrials.gov, none in the WHO International Clinical Trials Registry Platform and four from handsearching. We considered a total of 35 references to be potentially eligible. After reading the full text, we included these 35 records. They referred to three RCTs and 32 ancillary reports about these three primary studies. The flow diagram of the process of study identification and selection is presented in Figure 1. 


\section{Included studies}

The three RCTs included a total of 1713 participants (CAMMS223; CARE-MS I; CARE-MS II). All studies were multicentric trials, comparing alemtuzumab versus subcutaneous interferon beta-1a for patients with relapsing-remitting MS according to the McDonald criteria (McDonald 2001).

Participants were treatment-naive in the CARE-MS I and CAMMS223 studies. The CARE-MS II study included only participants with at least one relapse while being treated with interferon beta or glatiramer for at least six months.

In the CARE-MS I and CARE-MS II studies, the interventions were given for 12 months (CARE-MS I; CARE-MS II); in the CAMMS223 study, the treatment lasted 24 months (CAMMS223). The following regimens were used in these RCTs:

- CAMMS223 study, a phase II trial: alemtuzumab (either $12 \mathrm{mg}$ per day or $24 \mathrm{mg}$ per day) was given by intravenous infusion on five consecutive days during the first month and on three consecutive days at months 12 and 24 (CAMMS223).

- CARE-MS I (or CAMMS323) study, a phase III trial: alemtuzumab (12 mg per day) was given by intravenous infusion on five consecutive days during the first month and on three consecutive days at month 12 (CARE-MS I).

- CARE-MS II (or CAMMS324) study, a phase III trial: alemtuzumab (either $12 \mathrm{mg}$ per day or $24 \mathrm{mg}$ per day) was given by intravenous infusion on five consecutive days during the first month and on three consecutive days at month 12 (CARE-MS II).

In all studies, the dose of interferon beta-1a was $44 \mu \mathrm{g}$ given subcutaneously three times weekly after dose titration.

Details of these RCTs are available in the table Characteristics of included studies.

\section{Excluded studies}

We excluded none of the potentially eligible studies.

\section{Risk of bias in included studies}

The risk of bias of each study is detailed in the Characteristics of included studies table. Figure 2 and Figure 3 present the 'Risk of bias' summary along with review authors' judgements about each risk of bias item for each included study. The overall quality of the studies was low since in all of them we categorised at least one of the main domains (generation of allocation sequence, allocation concealment and blinding) as having a high risk of bias. 
Figure 2. 'Risk of bias' summary: review authors' judgements about each risk of bias item for each included study.

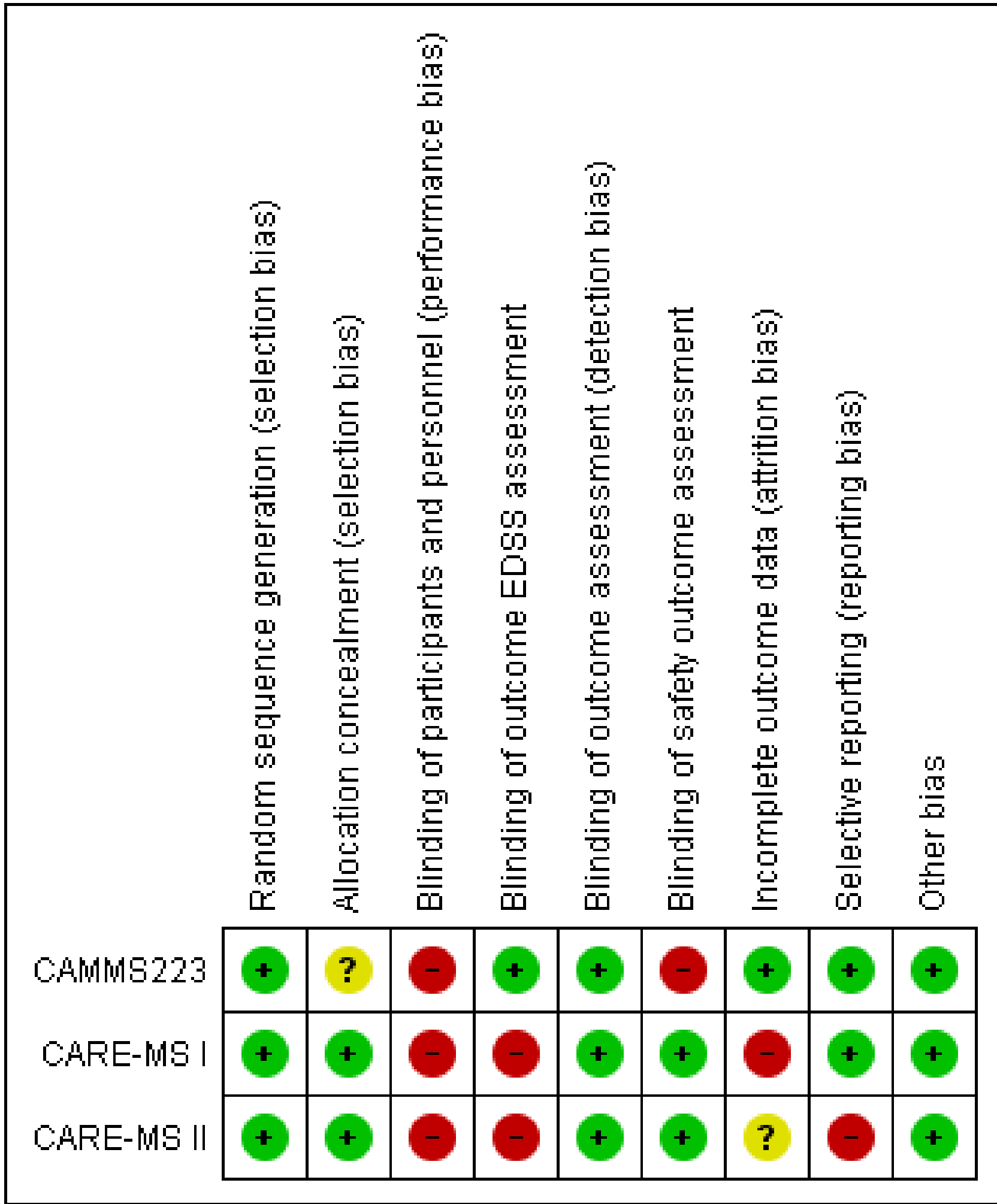


Figure 3. 'Risk of bias' graph: review authors' judgements about each risk of bias item presented as percentages across all included studies.

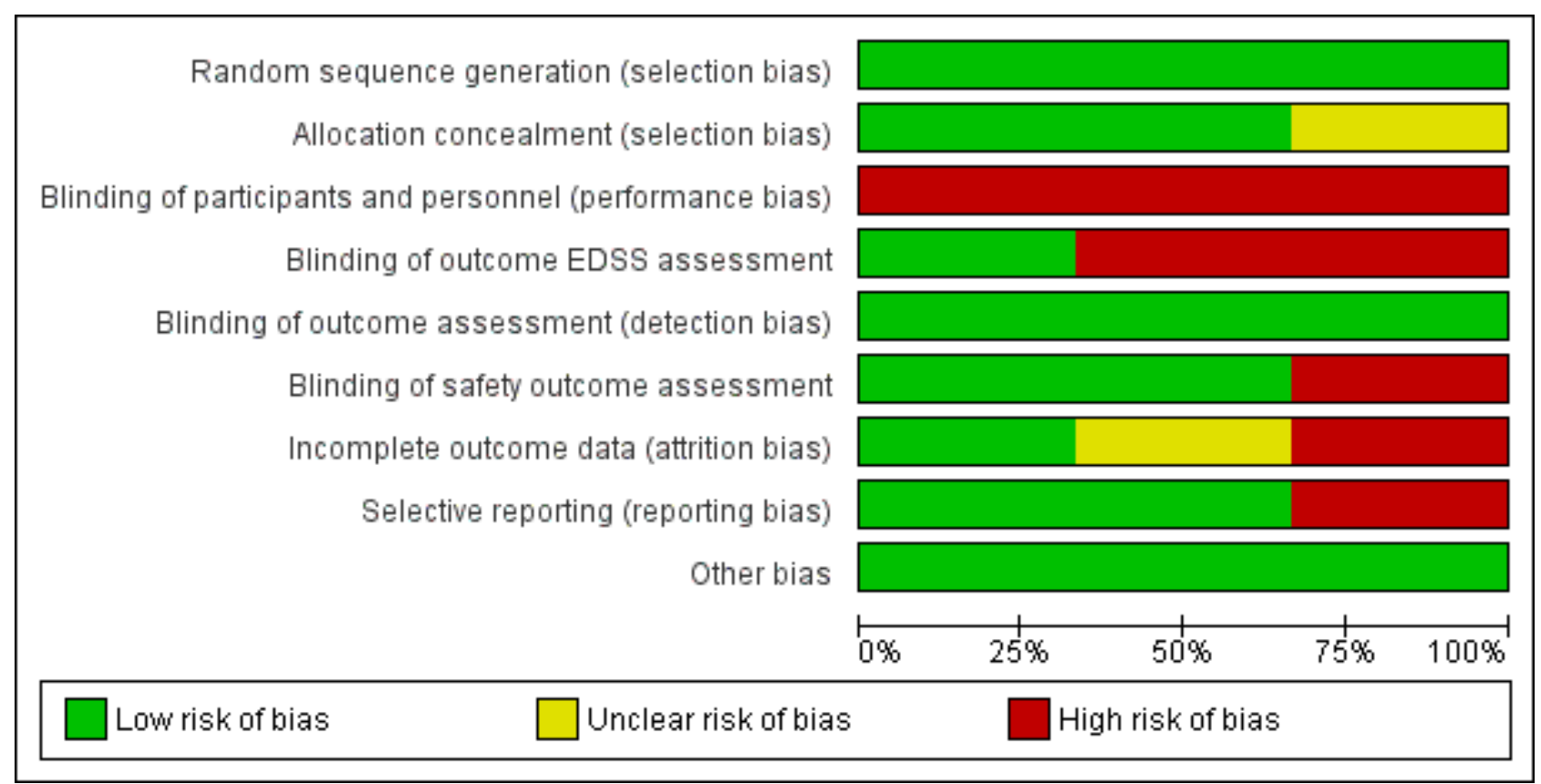

\section{Allocation}

We classified all studies as low risk of bias for generation of allocation sequence. The methods were reported in the articles and we judged them to be appropriate.

However, for allocation concealment, we classified one study as having an unclear risk of bias because it did not provide enough information to allow judgement (CAMMS223). We classified the other two studies as having a low risk of bias because they provided an adequate method to ensure allocation concealment (CARE-MS I; CARE-MS II).

\section{Blinding}

We considered all studies as having a high risk of bias of performance bias (participants and personnel) because both drugs (intervention and comparator) had adverse effects that precluded masking.

We judged the following outcomes separately for detection bias (outcome assessment):

- EDSS outcome assessment: We classified CARE-MS I and CARE-MS II as having a high risk of bias since unmasked raters performed the EDSS assessments. On the other hand, CAMMS223 had a low risk of bias.

- Efficacy outcomes assessment (except EDSS): We classified all studies as having a low risk of bias.

- Safety outcomes assessment: CARE-MS I and CARE-MS II had a low risk of bias, while CAMMS223 had a high risk of bias.

\section{Incomplete outcome data}

One study was at low risk of attrition bias (CAMMS223), one was at high risk because it used an inappropriate modified "intention- to-treat" analysis (CARE-MS I), and one study was at unclear risk of attrition bias (CARE-MS II)

\section{Selective reporting}

We classified two studies as having a low risk of selective reporting bias (CAMMS223; CARE-MS I). We classified one study as having high risk of bias because the results for some previously planned outcomes were not provided (i.e. quality of life) (CARE-MS II).

\section{Other potential sources of bias}

There were no other known potential sources of bias in the three included trials.

\section{Effects of interventions}

See: Summary of findings for the main comparison Alemtuzumab $12 \mathrm{mg}$ compared to interferon beta-1a for multiple sclerosis

\section{Comparison 1: Alemtuzumab 12 mg versus subcutaneous interferon beta-1a}

\section{Primary outcomes}

\section{Relapse-free survival}

Alemtuzumab was associated with better relapse-free survival at 24-month follow-up (hazard ratio (HR) 0.50, 95\% confidence interval $(\mathrm{Cl}) 0.41$ to $0.60 ; 1248$ participants; two studies; moderate quality evidence, $12=0 \%$ ) (Analysis 1.1; Figure 4). This result was consistent when we considered separately naive and previously treated participants. 
Figure 4. Forest plot of comparison: 1 Alemtuzumab 12 mg versus interferon beta-1a, outcome: 1.1 Relapse-free survival.

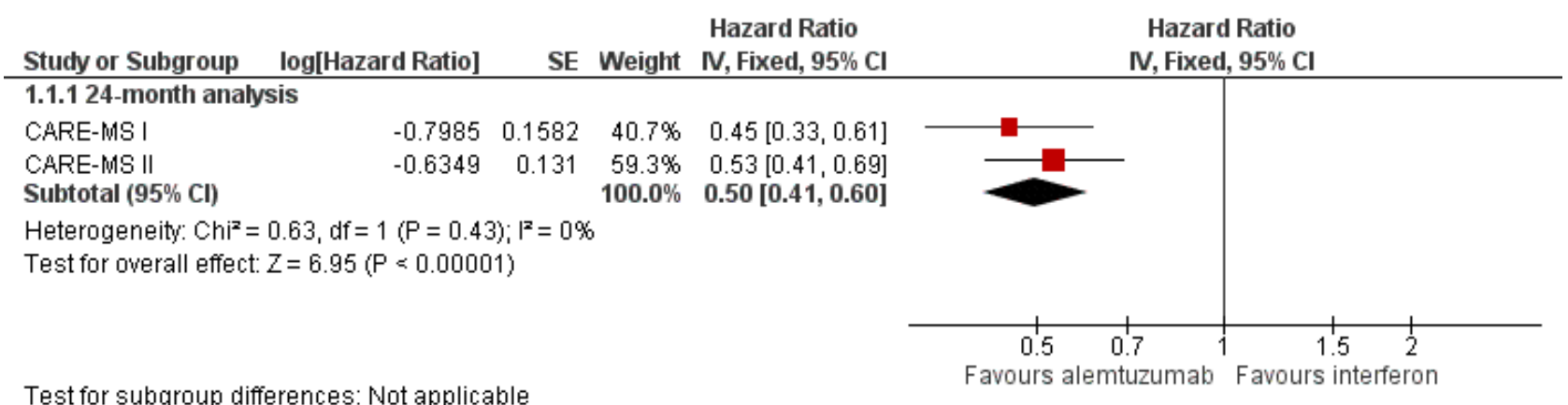

Only one study assessed this outcome at 36 months (CAMMS223). This study showed a higher number of participants who relapsed with interferon than with alemtuzumab ( 45 versus 24 ; HR $0.31,95 \%$ $\mathrm{Cl} 0.18$ to 0.52 ).

None of the included studies provided data for the 12-month analysis.

\section{Sustained disease progression-free survival}

Alemtuzumab was associated with a lower number of participants with sustained disease progression-free survival at both 24-month (HR $0.62,95 \% \mathrm{Cl} 0.44$ to $0.87 ; 1191$ participants; two studies; $\mathrm{I}^{2}$ $=0 \%$ ) and 36-month follow-up (HR $0.25,95 \% \mathrm{Cl} 0.11$ to 0.57 ; 223 participants; one study) (Analysis 1.2; Figure 5). This finding was consistent when we considered a subgroup of previously treated participants. However, for naive participants there was no difference between the interventions.

Figure 5. Forest plot of comparison: 1 Alemtuzumab 12 mg versus interferon beta-1a, outcome: 1.2 Sustained disease progression-free survival.

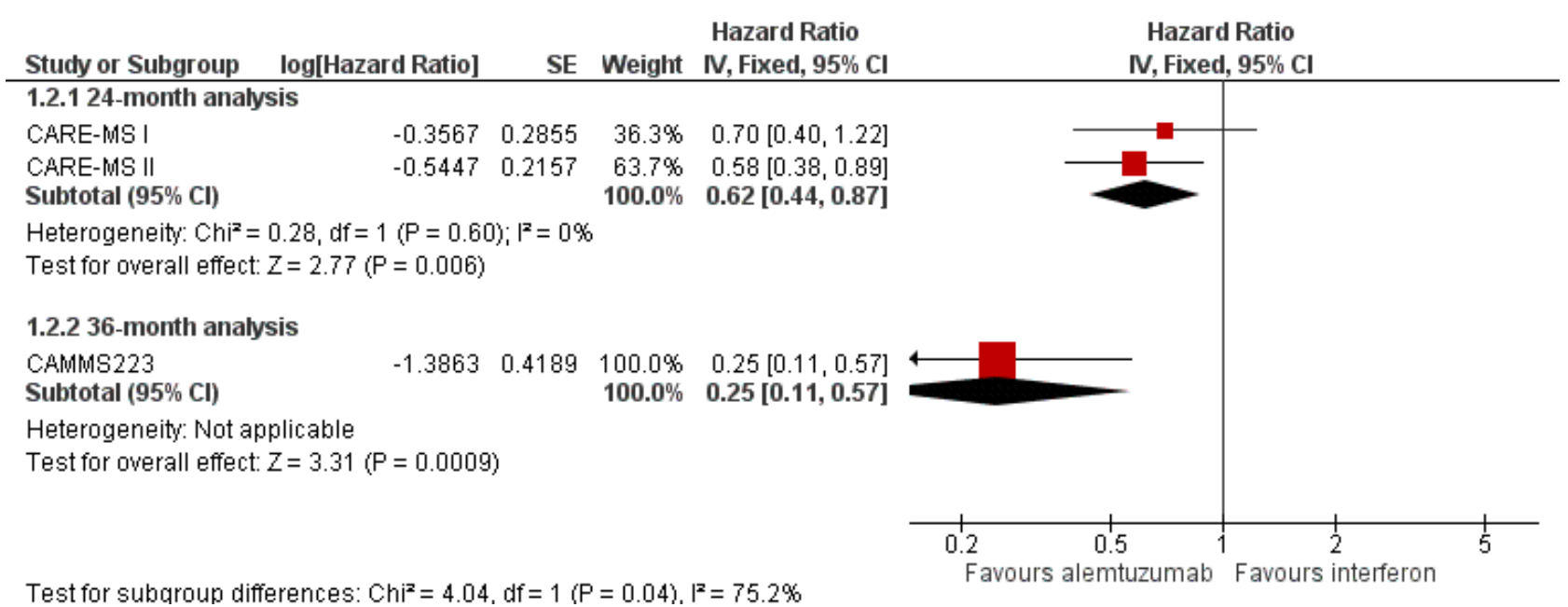

None of the included studies provided data for the 12-month analysis.

Number of participants with at least one adverse event, including serious adverse events

Alemtuzumab was associated with a higher proportion of participants with at least one adverse event after 24 months (risk ratio (RR) 1.04, 95\% Cl 1.01 to 1.06; 1248 participants; two studies; $1^{2}=0 \%$; moderate quality evidence), but not at 36 months (RR 1.00 , $95 \% \mathrm{Cl} 0.98$ to $1.02 ; 224$ participants; one study) (Analysis 1.3; Figure $6)$. 
Figure 6. Forest plot of comparison: 1 Alemtuzumab $12 \mathrm{mg}$ versus interferon beta-1a, outcome: 1.2 Rate of participants with at least one adverse event.

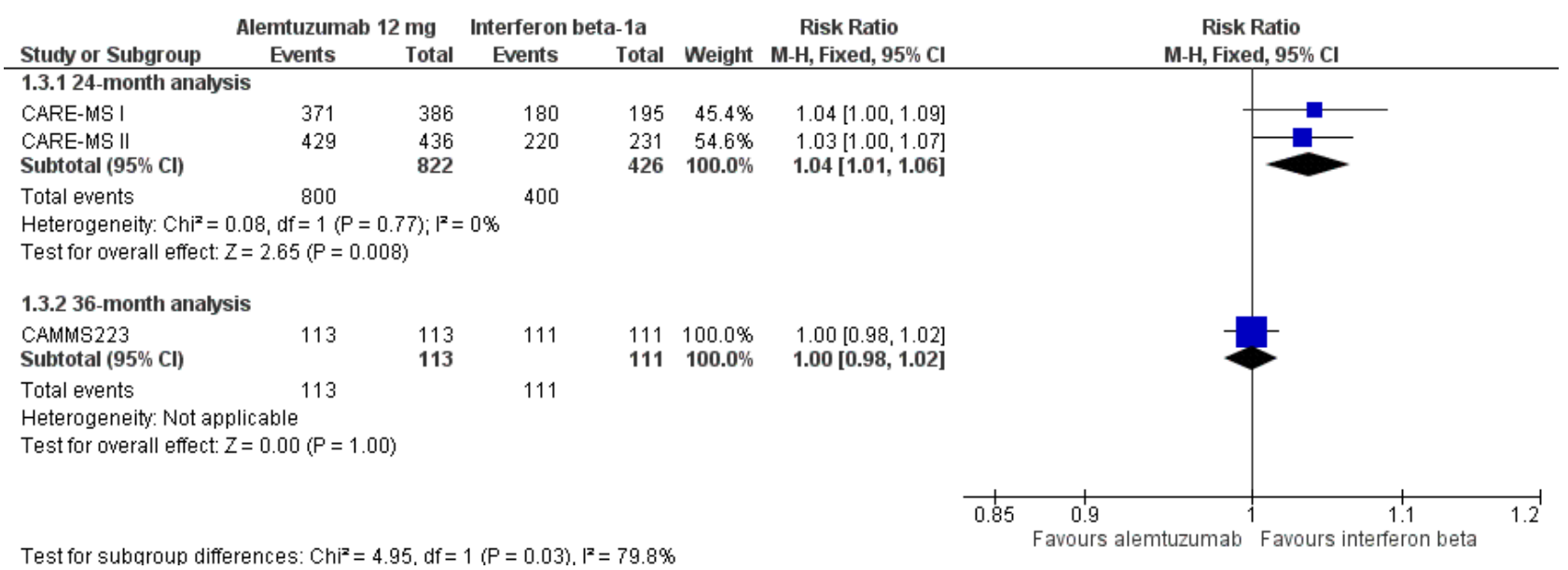

None of the included studies provided data for the 12-month analysis.

\section{Secondary outcomes}

Number of participants free of clinical disease activity

None of the included studies assessed this outcome.

\section{Quality of life}

None of the included studies assessed this outcome.

\section{Change in disability as assessed by the Expanded Disability Status} Scale (EDSS)

Alemtuzumab was associated with a significant improvement in EDSS scores after 36 months (mean difference (MD) -0.70, 95\% $\mathrm{Cl}-1.04$ to $-0.36 ; 223$ participants; one study) (CAMMS223). At 24 months, considering both treatment-naive patients and previously treated patients (who failed after interferon beta or glatiramer treatment), there were no differences in EDSS scores (MD -0.20, $95 \% \mathrm{Cl}-0.60$ to $0.20 ; 1199$ participants; two studies; $\mathrm{I}^{2}=88 \%$ ) (Analysis 1.4). However, when only previously treated patients were assessed, alemtuzumab was associated with better results (MD $-0.41,95 \% \mathrm{Cl}-0.62$ to -0.20 ; one study; 628 participants) (CARE-MS II).

None of the included studies provided data for the 12-month analysis.

\section{Fatigue as assessed by the Fatigue Severity Scale or the Fatigue Index} Scale

None of the included studies assessed this outcome.

Number of participants with new or enlarging T2-hyperintense lesions on magnetic resonance imaging

Alemtuzumab was associated with a lower rate of participants presenting with new or enlarging lesions, considering both naive and previously treated participants (RR $0.74,95 \% \mathrm{Cl} 0.59$ to 0.91 ; 1238 participants; two studies; $\mathrm{I}^{2}=80 \%$; random-effects model) (Analysis 1.5)

\section{Number of participants who dropped out}

Alemtuzumab was associated with a lower number of dropouts at 24 months (RR $0.31,95 \% \mathrm{Cl} 0.23$ to $0.41 ; 1248$ participants; two studies), but not at 36 months (RR $0.81,95 \% \mathrm{Cl} 0.57$ to $1.14 ; 224$ participants; one study) (Analysis 1.6).

None of the included studies provided data for the 12-month analysis.

\section{Comparison 2: Alemtuzumab $24 \mathrm{mg}$ versus subcutaneous interferon beta-1a}

\section{Primary outcomes}

\section{Relapse-free survival}

Only one study assessed this outcome at 36 months (CAMMS223). This study showed a higher number of relapses in the interferon group than in the alemtuzumab group (45 versus 17 ; HR $0.21,95 \%$ $\mathrm{Cl} 0.11$ to 0.40 ) (CAMMS223).

None of the included studies provided data for the 12- and 24month analyses.

\section{Sustained disease progression-free survival}

Alemtuzumab was associated with a lower number of participants with sustained disease progression-free survival at 36 months (HR $0.33,95 \% \mathrm{Cl} 0.16$ to $0.69 ; 221$ participants; one study) (CAMMS223).

None of the included studies provided data for the 12- or 24-month analyses.

Number of participants with at least one adverse event, including serious adverse events

There were no significant differences between alemtuzumab and subcutaneous interferon beta- $1 \mathrm{a}$ at 24 months (RR 1.04, 95\% Cl 1.00 to 1.07 ; 391 participants; one study) (CARE-MS II) or at 36 months (RR $0.99,95 \% \mathrm{Cl} 0.97$ to $1.02 ; 220$ participants; one study) (CAMMS223).

None of the included studies provided data for the 12-month analysis. 


\section{Secondary outcomes}

Number of participants free of clinical disease activity

None of the included studies assessed this outcome.

\section{Quality of life}

None of the included studies assessed this outcome.

\section{Change in disability as assessed by the EDSS}

Alemtuzumab was associated with a significant improvement in EDSS scores after 36 months (MD $-0.83,95 \% \mathrm{Cl}-1.17$ to $-0.49 ; 221$ participants; one study) (CAMMS223). None of the included studies provided data for the 12- and 24-month analyses.

\section{Fatigue as assessed by the Fatigue Severity Scale or the Fatigue Index} Scale

None of the included studies assessed this outcome.

Number of participants with new or enlarging T2-hyperintense lesions on magnetic resonance imaging

None of the included studies assessed this outcome.

\section{Number of participants who dropped out}

Alemtuzumab was associated with a lower number of dropouts at 24 months (RR $0.27,95 \% \mathrm{Cl} 0.16$ to 0.46 ; 404 participants; one study) (CARE-MS II), but not at 36 months (RR 0.76, 95\% CI 0.53 to $1.09 ; 221$ participants; one study) (CAMMS223).

None of the included studies provided data for the 12-month analysis.

\section{DISCUSSION}

\section{Summary of main results}

This systematic review aimed to assess the effects (benefits and harms) of alemtuzumab compared with any other drug treatment for any type of multiple sclerosis (MS).

Based on results of three randomised clinical trials (RCTs), compared to subcutaneous interferon beta-1a, alemtuzumab 12 mg was associated with:

- higher relapse-free survival at 24 months and 36 months;

- a lower number of participants with sustained disease progression-free survival;

- a slightly higher number of participants with at least one adverse event after 24 months;

- a higher improvement in Expanded Disability Status Scale (EDSS) scores after 36 months;

- a higher improvement in EDSS scores after 24 months (for patients previously treated with interferon or glatiramer acetate);

- a lower number of participants with new or enlarging T2hyperintense lesions on magnetic resonance imaging;

- a lower number of dropouts at 24 months, but not at 36 months.

Based on the results of one RCT, compared to subcutaneous interferon beta-1a, alemtuzumab $24 \mathrm{mg}$ was associated with:

- higher relapse-free survival at 36 months;
- a lower number of participants with sustained disease progression-free survival at 36 months;

- no statistical difference in the number of participants with at least one adverse event at 24 and 36 months;

- a higher improvement in EDSS scores after 36 months;

- a lower number of dropouts at 24 months, but not at 36 months.

The higher number of participants with at least one adverse event was not associated with a higher dropout rate probably because most of these events were mild or moderate. Data for severe adverse events were not provided separately by any of the included studies.

We included change in EDSS scores as a secondary outcome instead of a primary outcome because short-term changes in EDSS scores may not be a reliable marker of irreversible change in relapsingremitting MS (Healy 2013).

\section{Overall completeness and applicability of evidence}

We included three RCTs that compared alemtuzumab versus subcutaneous interferon beta- $1 \mathrm{a}$ in patients with relapsingremitting MS. Alemtuzumab was given during 12 or 24 months and the participants had a follow-up of up to 36 months for some outcomes in one of the included studies. The doses were (a) 12 $\mathrm{mg}$ or $24 \mathrm{mg}$ per day intravenously, once a day for five consecutive days at month 0 and 12, or (b) $24 \mathrm{mg}$ per day intravenously, once a day for three consecutive days at month 12 and 24. The control groups received interferon beta- $1 \mathrm{a}, 44 \mu \mathrm{g}$ subcutaneously three times weekly after dose titration. Therefore the available evidence is limited to these specific interventions and patients.

There is a lack of evidence for the following outcomes:

- number of participants free of clinical disease activity;

- quality of life;

- fatigue (assessed by the Fatigue Severity Scale or the Fatigue Index Scale, for example).

There are two probable reasons for this lack of evidence: (a) the outcomes were initially proposed in the trial protocols but were not available for this review even after contact with the authors of these studies; (b) the outcomes were not originally planned at the protocol stage of the included RCTs.

We must emphasise that the data at 36-month follow-up are based on a small number of participants and this can increase the uncertainty of these findings.

Finally, the three studies only included patients with relapsingremitting MS and we found no evidence for other forms of the disease.

\section{Quality of the evidence}

As presented in Summary of findings for the main comparison, the quality of the body of evidence obtained for each outcome ranged from very low to moderate.

The overall quality of the RCTs was low since in all of them we categorised at least one of the main domains (generation of allocation sequence, allocation concealment and blinding) as having a high risk of bias. In all studies, the participants and personnel were not blinded because the adverse effects related 
to each intervention preclude the masking. Additionally, in two studies the assessment of the EDSS scores could also be not blinded. Considering these two facts, we judged separately the risk of bias for EDSS and adverse events.

We noted no statistically significant heterogeneity among the studies for the co-primary outcomes. The quality of the evidence for dropouts was impaired by the low number of events in the trials.

\section{Potential biases in the review process}

To avoid the introduction of bias, we strictly followed all of the recommendations on searching, study selection, data collection, and data analysis from the Cochrane Handbook for Systematic Reviews of Interventions in this review (Higgins 2011).

The strengths of this review include a wide literature search and the use of intention-to-treat analyses for dichotomous data.

The limitations of this review include: (a) no assessment of publication bias through funnel plot analysis because there were fewer than 10 studies included in the meta-analysis and (b) the lack of some outcome data in the included RCTs.

\section{Agreements and disagreements with other studies or reviews}

During the conduct of this review a non-Cochrane systematic review assessing all available treatments for MS was published (CADTH 2013). This review evaluated direct and indirect comparisons between several drugs, including alemtuzumab. The findings are similar to those of our review, including the results of meta-analysis and the risk of bias of the included RCTs.

\section{AUTHORS' CONCLUSIONS}

\section{Implications for practice}

For patients with relapsing-remitting multiple sclerosis (MS), alemtuzumab $12 \mathrm{mg}$ was better than subcutaneous interferon beta-1a at 24 months for the outcomes relapse-free survival, sustained disease progression-free survival, adverse events, dropouts, Expanded Disability Status Scale (EDSS) scores (this last outcome only for patients previously treated with interferon beta or glatiramer acetate) and number of participants with new or enlarging T2-hyperintense lesions (very low to moderate quality evidence).

At 36 months, alemtuzumab $24 \mathrm{mg}$ improved the number of relapse-free patients, reduced the number of patients with sustained disease progression and had no effect on either the number of participants with at least one adverse event or dropouts.

There is a lack of evidence for the number of participants free of clinical disease activity, quality of life, fatigue and changes in lesions on magnetic resonance imaging.

When balancing the potential benefits and harms of this treatment, it is important to consider the risk of other autoimmune syndromes, thyroid disease and malignancies related to alemtuzumab (FDA 2014).

Although the trials assessed two different doses of alemtuzumab, the dose proposed for licensing was $12 \mathrm{mg} /$ day (Genzyme 2013). According to Genzyme, the reasons for this decision were that there was no difference between the $24 \mathrm{mg} /$ day and $12 \mathrm{mg} /$ day dose levels in the pharmacodynamic response and the overall frequency of adverse events was higher in the $24 \mathrm{mg}$ /day group, suggesting better tolerability of the $12 \mathrm{mg} /$ day dose. Additionally, the efficacy on imaging outcomes was reduced with the $12 \mathrm{mg} /$ day regimen, suggesting that larger reductions in dose would probably connote impairment in efficacy (Genzyme 2013).

\section{Implications for research}

Due to a lack of available data, more randomised clinical trials are needed to answer the following questions:

- Is alemtuzumab effective for other forms of MS besides relapsing-remitting MS?

- Is alemtuzumab effective for both naive and previously treated MS patients?

- Is alemtuzumab more effective than other available treatments (other than interferon beta-1a)?

- Are the observed effects of alemtuzumab sustained after 24 months?

- Are other doses and course durations of alemtuzumab effective for MS?

- What is the rate of each of the individual adverse events related to alemtuzumab (including autoimmune diseases and thyroiditis)?

- Does alemtuzumab improve quality of life, rate of progressionfree participants, rate of participants free of clinical disease activity, fatigue and change in MRI lesions?

- Are there long-term adverse events associated with the use of alemtuzumab in MS patients?

- Is alemtuzumab more effective and safe than other therapeutic options for MS?

\section{ACKNOWLEDGEMENTS}

The review authors would like to thank:

- the Cochrane Multiple Sclerosis and Rare Diseases of the Central Nervous System Review Group, especially Liliana Coco (Managing Editor) and Andrea Fittipaldo (Trials Search Coordinator) for their kind help;

- the reviewers (content experts and consumer representative), who provided useful comments and suggestions, including Loredana La Mantia and Lorenzo Brait.

- the Handbook Study Group from the Brazilian Cochrane Centre for methodological support;

- Cristine Migliorini for her effort and dedication in publishing the protocol for this review. 


\section{R E F E R E N C E S}

\section{References to studies included in this review}

CAMMS223 \{published data only\}

* Coles AJ, Compston DA, Selmaj KW, Lake SL, Moran S, Margolin DH, et al. Alemtuzumab vs. interferon beta-1a in early multiple sclerosis. New England Journal of Medicine 2008;359(17):1786-801.

Coles AJ, Fox E, Vladic A, Gazda SK, Brinar V, Selmaj KW, et al. Alemtuzumab more effective than interferon $\beta$-1a at 5-year follow-up of CAMMS223 clinical trial. Neurology 2012;78:106978.

Coles AJ, Fox E, Vladic A, Gazda SK, Brinar V, Selmaj KW, et al. Alemtuzumab versus interferon beta- $1 \mathrm{a}$ in early relapsingremitting multiple sclerosis: post-hoc and subset analyses of clinical efficacy outcomes. Lancet Neurology 2011;10(4):338-48.

Daniels GH, Vladic A, Brinar V, Zavalishin I, Valente W, Oyuela $P$, et al. Alemtuzumab-related thyroid dysfunction in a phase 2 trial of patients with relapsing-remitting multiple sclerosis. Journal of Clinical Endocrinology and Metabolism 2014;99(1):80-9.

\section{CARE-MS I \{published data only\}}

Arnold D, Brinar V, Cohen J, Coles A, Confavreux C, Fisher E, et al. Effect of alemtuzumab vs. RebifTM on brain MRI measurements: results of CARE-MS I, a phase 3 study. Neurology 2012;78(1):S11.006

* Cohen JA, Coles AJ, Arnold DL, Confavreux C, Fox EJ, Hartung HP, et al. Alemtuzumab versus interferon beta $1 \mathrm{a}$ as first-line treatment for patients with relapsing-remitting multiple sclerosis: a randomised controlled phase 3 trial. Lancet 2012;380(9856):1819-28.

Coles A, Brinar V, Arnold D, Cohen J, Confavreux C, Fox E, et al. Efficacy and safety results from comparison of alemtuzumab and RebifTM efficacy in multiple sclerosis I (CARE-MS I): a phase 3 study in relapsing-remitting treatment-naive patients. Neurology 2012;78(Suppl 1):S01.006.

Fox E, Arnold D, Brinar V, Cohen J, Coles A, Confavreux C, et al. Relapse outcomes with alemtuzumab vs. RebifTM in treatmentnaive relapsing-remitting multiple sclerosis (CARE-MS I): secondary and tertiary endpoints. Neurology 2012;78(Suppl 1):PD5.004. [DOI: 10.1212/WNL.78.1_MeetingAbstracts.PD5.004]

Giovannoni G, Arnold DL, Cohen J, Coles AJ, Confavreux C, Fox HP, et al. Disease activity-free status in comparison of alemtuzumab and RebifTM efficacy in multiple sclerosis I (CAREMS I) phase 3 study. Journal of Neurology 2012;259(Suppl 1):47.

Habek M, Arnold DL, Cohen J, Coles AJ, Confavreux C, Fox EJ, et al. Thyroid autoimmunity in comparison of Alemtuzumab and RebifTM efficacy in multiple sclerosis studies I and II. Journal of Neurology 2012;259(Suppl 1):66.

Havrdova E, Arnold DL, Cohen J, Coles AJ, Confavreux C, Fox EJ, et al. Infections Phase 3 study: comparison of alemtuzumab and
RebifTM efficacy in multiple sclerosis I (CARE-MS I). Neurology 2012;78(Suppl 1):S41.007.

Lycke J, Arnold DL, Cohen JA, Coles AJ, Confavreux C, Fox EJ, et al. Adverse event profile of alemtuzumab over time in treatment-naive patients with early, active relapsing-remitting multiple sclerosis (RRMS; CARE-MS I study). Journal of the Neurological Sciences 2013;333(Suppl 1):e374-5.

Lycke J, Arnold DL, Cohen JA, Coles AJ, Fox EJ, Hartung HP, et al. Adverse event profile of alemtuzumab in active relapsing remitting multiple sclerosis patients who participated in the CARE-MS studies: three-year follow-up. 29th Congress or the European Committee for Treatment and Research in Multiple Sclerosis (ECTRIMS), 2-5 October 2013, Copenhagen, Denmark. 2013.

Miller T, Arnold D, Cohen J, Coles A, Confavreux C, Fox E, et al. Detection, incidence, and management of thyroid autoimmunity in comparison of alemtuzumab and RebifTM in multiple sclerosis (CARE-MS) I and II. Neurology 2013;80(1):P01.173.

Selmaj K, Arnold DL, Brinar V, Cohen J, Coles AJ, Confavreux C, et al. Incidence of autoimmunity in a phase 3 trial: comparison of alemtuzumab and RebifTM in multiple sclerosis I (CARE-MS I). Neurology 2012;78(1):S41.006.

Selmaj K, Arnold DL, Cohen J, Coles AJ, Confavreux C, Fox EJ, et al. Alemtuzumab improves patient-reported quality of life in relapsing-remitting multiple sclerosis: CARE-MS I and II phase 3 trials. Journal of Neurology 2012;259(Suppl 1):S65-6.

\section{CARE-MS II \{published data only\}}

Arnold DL, Cohen J, Coles AJ, Confavreux C, Fisher E, Fox EJ, et al. Effect of alemtuzumab vs. Rebif ${ }^{\oplus}$ on brain MRI measurements. Multiple Sclerosis 2012;18(4):397.

Arroyo R, Arnold DL, Cohen JA, Coles AJ, Confavreux C, Fox EJ, et al. Alemtuzumab improves quality of life compared to SC IFNB-1a in CARE-MS II. Journal of Neurology 2013;260:S121-2.

Barkhof F, Fisher E, Palmer J, Margolin DH, Arnold DL. Alemtuzumab demonstrates improvement in MRI outcomes across baseline subgroups versus subcutaneous interferon beta-1a in relapsing-remitting multiple sclerosis patients who relapsed on prior therapy. European Journal of Neurology 2014;21:126-7.

Brinar V, Arnold DL, Cohen J, Coles AJ, Fox EJ, Hartung HP, et al. Alemtuzumab improves expanded disability status scale (EDSS) via effects on functional systems: CARE-MS II. Multiple Sclerosis. Multiple Sclerosis Journal 2013;19(S1):283-4.

* Coles AJ, Twyman CL, Arnold DL, Cohen JA, Confavreux C, Fox EJ, et al. Alemtuzumab for patients with relapsing multiple sclerosis after disease-modifying therapy: a randomised controlled phase 3 trial. Lancet 2012;380:1829-39.

Confavreux C, Twyman CL, Arnold D, Cohen J, Coles AJ, Fox EJ, et al. Efficacy of alemtuzumab in relapsing remitting multiple 
sclerosis (RRMS) patients with highly active disease despite therapy. European Journal of Neurology 2012;19(Suppl 1):458.

Fernandez O, Arnold DL, Cohen JA, Coles AJ, Confavreux C, Fox EJ, et al. Alemtuzumab improves disability by month 6 independent of relapse history in relapsing-remitting multiple sclerosis patients: CARE-MS II 20620. Journal of Neurology 2013;260:S14.

Fisher E, Barkhof F, Cohen JA, Fox EJ, Selmaj KW, Margolin DH, et al. Alemtuzumab improves MRI outcomes in relapsingremitting multiple sclerosis patients who relapsed on prior therapy: three-year follow-up of CARE-MS II. Multiple Sclerosis Journal 2014;20(Suppl 1):67.

Giovannoni G, Arnold DL, Cohen J, Coles AJ, Confavreux C, Fox $\mathrm{E}$, et al. Disability improvement with alemtuzumab vs. interferon $b$ - $1 a$ in relapsing-remitting multiple sclerosis patients who relapsed on prior therapy (CARE-MS II). Multiple Sclerosis 2012;18(S1):419.

Giovannoni G, Arnold DL, Cohen J, Coles AJ, Confavreux C, Fox E, et al. Multiple sclerosis: clinical trials outcomes disability improvement with alemtuzumab vs. interferon beta-1a in relapsing-remitting multiple sclerosis patients who experienced disease activity while on prior therapy (CARE-MS II). Neurology 2013;80(Suppl 1):P07.120.

Habek M, Arnold DL, Cohen J, Coles AJ, Confavreux C, Fox EJ, et al. Thyroid autoimmunity in comparison of alemtuzumab and RebifTM efficacy in multiple sclerosis studies I and II. Journal of Neurology 2012;259(Suppl 1):S66.

Hartung H, Vollmer T, Arnold D, Cohen J, Coles A, Confavreux C, et al. Alemtuzumab reduces $m s$ disease activity in active relapsing-remitting multiple sclerosis patients who had disease activity on prior therapy. Neurology 2013;80(Suppl 1):P07.093.

Hartung HP, Arnold DL, Cohen J, Coles AJ, Confavreux C, Fox EJ, et al. Disability outcomes for alemtuzumab in RRMS patients who relapsed on prior therapy: CARE-MS II. Journal of Neurology 2012;259(Suppl 1):S47-8.

Havrdova E, Arnold DL, Cohen J, Coles AJ, Confavreux C, Fox EJ, et al. Safety of alemtuzumab in relapsing-remitting multiple sclerosis patients who relapsed on prior therapy (CARE-MS II). Multiple Sclerosis 2012;18(4):235.

Lycke J, Arnold DL, Cohen JA, Coles AJ, Fox EJ, Hartung HP, et al. Adverse event profile of alemtuzumab in active relapsing remitting multiple sclerosis patients who participated in the CARE-MS studies: three-year follow-up. 29th Congress of the European Committee for Treatment and Research in Multiple Sclerosis (ECTRIMS), 2-5 October 2013, Copenhagen, Denmark 2013;19(S1):487-8.

Miller T, Arnold D, Cohen J, Coles A, Confavreux C, Fox E, et al. Detection, incidence, and management of thyroid autoimmunity in comparison of alemtuzumab and RebifTM in multiple sclerosis (CARE-MS) I and II. Neurology 2013;80(1):P01.173.

Moreau T, Margolin DH, Kasten L, Singer B. Alemtuzumab improves quality of life in relapsing remitting multiple sclerosis patients who relapsed on prior therapy: 3-year follow-up of CARE-MS II. Multiple Sclerosis 2014;20(1):86.

Selmaj K, Arnold DL, Cohen J, Coles AJ, Confavreux C, Fox EJ, et al. Alemtuzumab improves patient-reported quality of life in relapsing-remitting multiple sclerosis: CARE-MS I and II phase 3 trials. Journal of Neurology 2012;259(Suppl 1):S65-6.

Wray S, Arnold D, Cohen J, Coles A, Confavreux C, Fox E, et al. Comparison of infection risk with alemtuzumab and $\mathrm{sc}$ IFNB-1a in patients with multiple sclerosis who experienced disease activity while on prior therapy (CARE-MS II). Neurology 2013;80(1):P01.172.

\section{Additional references \\ CADTH 2013}

Canadian Agency for Drugs and Technologies in Health. Management of relapsing-remitting multiple sclerosis. http:// www.ncbi.nlm.nih.gov/books/NBK169748/ (accessed 11 March 2016).

\section{Coles 1999a}

Coles AJ, Wing M, Smith S, Coraddu F, Greer S, Taylor C, et al. Pulsed monoclonal antibody treatment and autoimmune thyroid disease in multiple sclerosis. Lancet 1999;354:1691-5.

\section{Coles 1999b}

Coles AJ, Wing MG, Molyneux P, Paolillo A, Davie CM, Hale G, et al. Monoclonal antibody treatment exposes three mechanisms underlying the clinical course of multiple sclerosis. Annals of Neurology 1999;46:296-304.

\section{Coles 2006}

Coles AJ, Cox A, Le Page E, Jones J, Trip SA, Deans J, et al. The window of therapeutic opportunity in multiple sclerosis: evidence from monoclonal antibody therapy. Journal of Neurology 2006;253:98-108.

\section{Cossburn 2011}

Cossburn M, Pace AA, Jones J, Ali R, Ingram G, Baker K, et al. Autoimmune disease after alemtuzumab treatment for multiple sclerosis in a multicenter cohort. Neurology 2011;77(6):573-9.

\section{EMA 2013}

European Medicines Agency. Lemtrada - Committee for Medicinal Products for Human Use (CHMP) - Assessment report. http://www.ema.europa.eu/docs/en_GB/document library/EPAR_-_Public_assessment_report/human/003718/ WC500150522.pdf (accessed 11 March 2016).

\section{FDA 2001}

US Food, Drug Administration. Campath (alemtuzumab) Product Approval Information - Application number BLA 103948/0. http://www.accessdata.fda.gov/drugsatfda_docs/ nda/2000/103948_0000_Campath_AprvbleLtr2.pdf (accessed 11 March 2016).

\section{FDA 2014}

US Food, Drug Administration. Alemtuzumab (Lemtrada) Product Approval Information. Licensing Action 2014. 
http://www.accessdata.fda.gov/drugsatfda_docs/ appletter/2014/1039480rig1s5139ltr.pdf (accessed 11 March 2016).

\section{FDA 2015}

US Food, Drug Administration. Risk Evaluation and Mitigation Strategies (REMS). Lemtrada 2015. http:// www.accessdata.fda.gov/scripts/cder/rems/index.cfm? event=IndvRemsDetails.page\&REMS=340 (accessed 11 March 2016).

\section{Filippini 2013}

Filippini G, Del Giovane C, Vacchi L, D'Amico R, Di Pietrantonj C, Beecher D, et al. Immunomodulators and immunosuppressants for multiple sclerosis: a network meta-analysis. Cochrane Database of Systematic Reviews 2013, Issue 6. [DOI: 10.1002/14651858.CD008933.pub2]

\section{Fischer 1999}

Fischer JS, LaRocca NG, Miller DM, Ritvo PG, Andrews H, Paty D. Recent developments in the assessment of quality of life in multiple sclerosis (MS). Multiple Sclerosis 1999;5:251-9.

\section{Genzyme 2013}

Peripheral and Central Nervous System Drugs Advisory Committee. Alemtuzumab Advisory Committee Briefing Document. BLA 103948. http://www.fda.gov/downloads/ AdvisoryCommittees/CommitteesMeetingMaterials/Drugs/ PeripheralandCentralNervousSystemDrugsAdvisoryCommittee/ UCM374188.pdf (accessed 11 March 2016).

\section{Gilleece 1993}

Gilleece M, Dexter T. Effect of campath-1h antibody on human hematopoietic progenitors in vitro. Blood 1993;82:807-12.

\section{Gomez-Almaguer 2012}

Gomez-Almaguer D, Jaime-Perez J, Ruiz-Arguelles G. Antibodies in the treatment of aplastic anaemia. Archivum Immunologiae et Therapiae Experimentalis 2012;60:99-106.

\section{GRADEpro 2008 [Computer program]}

GRADE Working Group. GRADEpro. Version 3.2 for Windows. GRADE Working Group, 2008.

\section{Gray 2004}

Gray O, McDonnell GV, Forbes RB. Methotrexate for multiple sclerosis. Cochrane Database of Systematic Reviews 2004, Issue 2. [DOI: 10.1002/14651858.CD003208.pub2]

\section{Hawkins 1999}

Hawkins SA, McDonnell GV. Benign multiple sclerosis? Clinical course, long term follow up, and assessment of prognostic factors. Journal of Neurology Neurosurgery and Psychiatry 1999;67:148-52.

\section{Healy 2013}

Healy BC, Engler D, Glanz B, Musallam A, Chitnis T. Assessment of definitions of sustained disease progression in relapsingremitting multiple sclerosis. Multiple Sclerosis International 2013;2013:189624. [PUBMED: 23555057]

\section{Higgins 2011}

Higgins JPT, Green S (editors). Cochrane Handbook for Systematic Reviews of Interventions. Version 5.1.0 [updated March 2011]. The Cochrane Collaboration, 2011. www.cochranehandbook.org.

\section{Hill-Cawthorne 2012}

Hill-Cawthorne GA, Button T, Tuohy O, Jones JL, May K, Somerfield J, et al. Long term lymphocyte reconstitution after alemtuzumab treatment of multiple sclerosis. Journal of Neurology, Neurosurgery and Psychiatry 2012;83(3):298-304.

\section{Hirst 2008}

Hirst CL, Pace A, Pickersgill TP, Jones R, McLean BN, Zajicek JP, et al. Campath1-H treatment in patients with aggressive relapsing remitting multiple sclerosis. Journal of Neurology 2008;255:231-8.

\section{Keating 2002}

Keating M, Flinn I, Jain V, Binet J, Hillmen P, Byrd J, et al. Therapeutic role of alemtuzumab (Campath-1H) in patients who have failed fludarabine: results of a large international study. Blood 2002;99:3554-61.

\section{Krupp 1989}

Krupp LB, LaRocca NG, Muir-Nash J, Steinberg AD. The fatigue severity scale. Application to patients with multiple sclerosis and systemic lupus erythematosus. Archives of Neurology 1989;46:1121-3.

\section{Kurtzke 1983}

Kurtzke JF. Rating neurologic impairment in multiple sclerosis: an expanded disability status scale. Neurology 1983;33:1444-52.

\section{Li 1999}

Li DK, Paty DW, the UBC MS/MRI Analysis Research Group and the PRISMS Study Group. Magnetic resonance imaging results of the PRISMS trial: a randomised, double-blind, placebocontrolled study of interferon-beta la in relapsing-remitting multiple sclerosis. Annals of Neurology 1999;46:197-206.

\section{Lockwood 2003}

Lockwood C, Hale G, Waldmann H, Jayne D. Remission induction in Behcet's disease following lymphocyte depletion by the anti-CD52 antibody CAMPATH-1H. Rheumatology 2003;42:1539-44.

\section{Lublin 1996}

Lublin FD, Reingold SC. Defining the clinical course of multiple sclerosis: results of an international survey. Neurology 1996;46:907-11.

\section{McDonald 2001}

McDonald WI, Compston A, Edan G, Goodkin D, Hartung HP, Lublin FD, et al. Recommended diagnostic criteria for multiple sclerosis: guidelines from the International Panel on the Diagnosis of Multiple Sclerosis. Annals of Neurology 2001;50:121-7. 


\section{Multiple Sclerosis International Federation 2010}

Multiple Sclerosis International Federation (MSIF). Global Economic Impact of Multiple Sclerosis. http://www.msif.org/ wp-content/uploads/2014/09/Global_economic_impact_of_ MS.pdf (accessed 11 March 2016).

\section{Noseworthy 2000}

Noseworthy JH, Lucchinetti C, Rodriguez M, Weinshenker BG. Multiple sclerosis. New England Journal of Medicine 2000;343(13):938-52.

\section{Polman 2011}

Polman CH, Reingold SC, Banwell B, Clanet M, Cohen JA, Filippi M, et al. Diagnostic criteria for multiple sclerosis: 2010 revisions to the McDonald criteria. Annals of Neurology 2011;69(2):292-302

\section{Poser 1983}

Poser CM, Paty DW, Scheinberg L, McDonal WI, Davis FA, Ebers GC. New diagnostic criteria for multiple sclerosis: guidelines for research protocols. Annals of Neurology 1983;13:227-31.

\section{Rao 2012}

Rao SP, Sancho J, Campos-Rivera J, Boutin PM, Severy PB, Weeden $\mathrm{T}$, et al. Human peripheral blood mononuclear cells exhibit heterogeneous CD52 expression levels and show differential sensitivity to alemtuzumab mediated cytolysis. PLoS One 2012;7(6):e39416.

\section{RevMan 2015 [Computer program]}

The Nordic Cochrane Centre, The Cochrane Collaboration. Review Manager (RevMan). Version 5.3. Copenhagen: The Nordic Cochrane Centre, The Cochrane Collaboration, 2015.

\section{Rieckmann 2009}

Rieckmann P. Concepts of induction and escalation therapy in multiple sclerosis. Journal of Neurosurgical Sciences 2009;277(Suppl 1):42-5.

\section{CHARACTERISTICS OF STUDIES}

Characteristics of included studies [ordered by study ID]

\section{Scolding 2015}

Scolding N, Barnes D, Cader S, Chataway J, Chaudhuri A, Coles A, et al. Association of British Neurologists: revised (2015) guidelines for prescribing disease-modifying treatments in multiple sclerosis. Practical Neurology 2015;15(4):273-9.

\section{Vickrey 1995}

Vickrey BG, Hays RD, Harooni R, Myers LW, Ellison GW. A healthrelated quality of life measure for multiple sclerosis. Quality of Life Research 1995;4(3):187-206.

\section{Waldmann 2005}

Waldmann H, Hale G. Campath: from concept to clinic. Philosophical transactions of the Royal Society B: Biological Sciences 2005;360:1707-11.

\section{Weissenbacher 2010}

Weissenbacher A, Boesmueller C, Brandacher G, Oellinger R, Pratschke J, Schneeberger S. Alemtuzumab in solid organ transplantation and in composite tissue allotransplantation. Immunotherapy 2010;2:783-90.

\section{Xia 1991}

Xia M, Tone M, Packman L, Hale G, Waldmann H. Characterization of the Campath-1 (CDW2) antigen: biochemical analysis and CDNA cloning reveal an unusually small peptide backbone. European Journal of Immunology 1991;21:1677-84.

\section{References to other published versions of this review Riera 2014}

Riera R, Porfirio G, Migliorini CR, Torloni MR. Alemtuzumab for multiple sclerosis. Cochrane Database of Systematic Reviews 2014, Issue 7. [DOI: 10.1002/14651858.CD011203]

* Indicates the major publication for the study

\section{CAMMS223}

$\begin{array}{ll}\text { Methods } & \text { CAMMS223 (primary reference) } \\ & \text { - Multicentric, phase II, randomised clinical trial } \\ & -49 \text { centres in Europe and the United States } \\ & - \text { Randomisation ratio } 1: 1: 1 \text {, stratification to balance the study groups with regard to age (<30 years or } \\ & \geq 30 \text { years), gender and baseline EDSS scores }(<2.0 \text { or } \geq 2.0) \\ & -\mathrm{N}=334 \text { /available for analysis }=333 \\ \text { - } & \text { Treatment duration: } 24 \text { months } \\ \text { - } & \text { Follow-up duration: } 36 \text { months }\end{array}$

Participants

Inclusion criteria

- Diagnosis of relapsing-remitting MS based on the McDonald criteria

- Onset of symptoms no more than 36 months before the time of screening; at least 2 clinical episodes during the previous 2 years; a score of 3 or less on the EDSS, which ranges from 0 to 10 , with higher 
scores indicating greater disability; and one or more enhancing lesions, as seen on at least one of up to 4 monthly cranial magnetic resonance imaging (MRI) scans.

\section{Exclusion criteria}

- Previous disease-modifying treatments

- History of clinically significant autoimmunity

- Presence of serum antithyrotropin-receptor antibodies
Main interventions

- Alemtuzumab $12 \mathrm{mg}$ administered IV, once a day for 5 consecutive days at the first month and for 3 consecutive days at months 12 and 24 (the latter at the treating physicians' discretion if the CD4+ Tcell count was $\geq 100 \times 106$ cells/L) ( $n=113$ /available for analysis $=112$ )

- Alemtuzumab $24 \mathrm{mg}$ administered IV, once a day for 5 consecutive days at the first month and for 3 consecutive days at months 12 and 24 (the latter at the treating physicians' discretion if the CD4+ Tcell count was $\geq 100 \times 106$ cells $/ L)(n=110 /$ available for analysis $=110)$

\section{Comparator}

- Interferon beta-1a (44 $\mu \mathrm{g})$ administered subcutaneously 3 times weekly after dose escalation ( $\mathrm{n}=111$ / available for analysis $=111$ )

All participants received $1 \mathrm{~g}$ of intravenous methylprednisolone for 3 days at baseline and at months 12 and 24 , coinciding with infusion cycles as premedication for those receiving alemtuzumab. Some participants also received antihistamines or antipyretics at the investigators' discretion

Primary outcome measure

- Rate of participants with sustained accumulation of disability: Disability was assessed according to the ordinal EDSS score. A sustained accumulation of disability was defined as an increase of at least 1.5 points for participants with a baseline score of 0 and of at least 1.0 point for participants with a baseline score of 1.0 or more; all scores were confirmed twice during a 3 - and 6-month period. The onset of a sustained level of disability was timed to the first recorded increase in the EDSS score aside from relapse.

- Rate of relapse: Relapse was defined as new or worsening symptoms with an objective change in neurologic examination attributable to multiple sclerosis that lasted for at least 48 hours, that were present at normal body temperature, and that were preceded by at least 30 days of clinical stability.

Secondary outcome measures

- Proportion of participants who did not have a relapse (proportion of participants with relapse-free survival)

- Changes in lesion burden (as seen on T2-weighted MRI)

- Brain volume (as measured by the Losseff method on T1-weighted MRI8)

- Adverse effects, including the following measures:

- Thyroid function and levels of antithyrotropin receptor antibodies and lymphocyte subpopulations were measured quarterly at a central laboratory

- Serum-binding antibodies against alemtuzumab were measured with the use of a validated enzyme-linked immunosorbent assay (ELISA) at BioAnaLab

- Immune thrombocytopenia by single confirmed platelet count of fewer than 50,000 per microlitre without clumping or a platelet count of more than 50,000 but fewer than 100,000 per microlitre on at least 2 consecutive occasions during a period of at least 1 month, with normal haemoglobin, neutrophil and eosinophil counts; an absence of splenomegaly; and a normal peripheral-blood smear (apart from thrombocytopenia).

All adverse events with an onset up to 36 months were reported. In addition, all serious adverse events and autoimmune-associated disorders occurring before 1 March 2008, were listed. A subsequent adverse event of Burkitt's lymphoma not associated with Epstein-Barr virus (EBV) was also included in this report. 
CAMMS223 (Continued)

Notes
- The effectiveness of blinding was assessed at the end-of-study visit.

- Participants with an increased level of disability could be discontinued from the study.

- There was no active monitoring for progressive multifocal leukoencephalopathy.

- Preplanned interim analyses were performed when most participants had completed at least 1 year and 2 years with a prespecified alpha spending function. Disclosure of these results formed part of safety announcements by the sponsor in September 2005 and 2006. After the interim analyses, P values of less than 0.016 and 0.004 were considered to have statistical significance for the rates of sustained disability and relapse, respectively.

- In September 2005, the data and safety monitoring board recommended suspension of alemtuzumab treatments after receiving reports of 3 cases of immune thrombocytopenic purpura, including 1 death. All safety and efficacy assessments proceeded as planned and participants who were receiving interferon beta-1a continued to receive the drug. At the time of dose suspension, only 2 eligible participants $(1 \%)$ had not received the second cycle of alemtuzumab at month 12, whereas 155 participants $(75 \%)$ were precluded from receiving the third cycle of alemtuzumab at month 24.

- More participants discontinued interferon beta-1a than alemtuzumab, principally because of a lack of efficacy and adverse events, so that only 59\% of the original group of participants receiving interferon beta-1a completed the 36 -month study, as compared with $83 \%$ of participants receiving alemtuzumab. At the end of the study review, $90 \%$ and $91 \%$ of raters remained unaware of assignments to the group receiving interferon beta- 1 a and the group receiving alemtuzumab, respectively.

- Funding: Genzyme

\section{Risk of bias}

\begin{tabular}{|c|c|c|}
\hline Bias & Authors' judgement & Support for judgement \\
\hline $\begin{array}{l}\text { Random sequence genera- } \\
\text { tion (selection bias) }\end{array}$ & Low risk & $\begin{array}{l}\text { Eligible participants were randomly assigned in a 1:1:1 with the use of the } \\
\text { Pocock and Simon minimisation algorithm. }\end{array}$ \\
\hline $\begin{array}{l}\text { Allocation concealment } \\
\text { (selection bias) }\end{array}$ & Unclear risk & No information available to allow a judgement \\
\hline $\begin{array}{l}\text { Blinding of participants } \\
\text { and personnel (perfor- } \\
\text { mance bias) } \\
\text { All outcomes }\end{array}$ & High risk & $\begin{array}{l}\text { Both study drugs have adverse effects that precluded masking of participants } \\
\text { and treating clinicians to treatment assignment }\end{array}$ \\
\hline $\begin{array}{l}\text { Blinding of outcome EDSS } \\
\text { assessment } \\
\text { EDSS }\end{array}$ & Low risk & $\begin{array}{l}\text { "EDSS scores were determined quarterly in a blinded fashion by a neurologist } \\
\text { who also adjudicated possible relapses". }\end{array}$ \\
\hline $\begin{array}{l}\text { Blinding of outcome as- } \\
\text { sessment (detection bias) } \\
\text { All outcomes, except } \\
\text { EDSS }\end{array}$ & Low risk & $\begin{array}{l}\text { "MRI scans were performed annually and interpreted by a neuroradiologist who } \\
\text { was unaware of assignments to study groups". }\end{array}$ \\
\hline $\begin{array}{l}\text { Blinding of safety outcome } \\
\text { assessment }\end{array}$ & High risk & $\begin{array}{l}\text { "Safety was assessed quarterly by the treating neurologist, who was aware of } \\
\text { study-group assignment". }\end{array}$ \\
\hline $\begin{array}{l}\text { Incomplete outcome data } \\
\text { (attrition bias) } \\
\text { All outcomes }\end{array}$ & Low risk & $\begin{array}{l}\text { Number and reasons of withdrawals were similar in the interventions and con- } \\
\text { trol arms. }\end{array}$ \\
\hline $\begin{array}{l}\text { Selective reporting (re- } \\
\text { porting bias) }\end{array}$ & Low risk & - \\
\hline Other bias & Low risk & - \\
\hline
\end{tabular}




- CARE-MS I (primary reference)
- Multicentric, phase III, randomised clinical trial
- 101 academic medical centres and clinical practices in 16 countries
- Randomisation ratio $2: 1$; stratification by site
- $\mathrm{N}=581$ /available for analysis $=563$
- Treatment duration: 12 months
- Follow-up duration: 24 months

Participants

Inclusion criteria

- 18 to 50 years of age

- Diagnosis of relapsing-remitting multiple sclerosis fulfilling the McDonald criteria

- Disease duration of up to 5 years

- At least 2 relapses in the previous 2 years and at least 1 in the previous year

- Expanded disability status scale (EDSS) 10 scores of 3.0 or lower

- Cranial abnormalities on MRI attributable to multiple sclerosis

\section{Exclusion criteria}

- Progressive disease course

- Previous multiple sclerosis disease therapy (apart from corticosteroids)

- Previous immunosuppressive, investigational or monoclonal antibody therapy

- Clinically significant autoimmunity other than multiple sclerosis

- Alemtuzumab $12 \mathrm{mg}$ administered IV, once a day for 5 consecutive days at baseline and for 3 consecutive days at 12 months $(n=386$ /available for analysis $=376)$

After a protocol amendment in January 2009, alemtuzumab participants received oral aciclovir $200 \mathrm{mg}$ twice daily during alemtuzumab infusion and for 28 days thereafter as prophylaxis against herpes infection.

\section{Comparator}

- Interferon beta-1a 44 $\mu$ g given subcutaneously 3 times weekly after dose titration ( $n=195 /$ available for analysis $=187$ )

Participants in both groups received $1 \mathrm{~g}$ per day of intravenous methylprednisolone on 3 consecutive days at baseline and at month 12 . Concomitant treatment with an antipyretic or antihistamine drug was allowed, at the discretion of the treating neurologist.

- Relapse rate, defined as new or worsening neurological symptoms attributable to MS, lasting at least 48 hours, without pyrexia, after at least 30 days of clinical stability, with an objective change on neurological examination assessed by a masked rater. The relapse adjudication panel decided the status of suspected relapses on the basis of the protocol definition and their masked review of all data collected by the site, including whether there was an objective change corresponding to current relapse symptoms ( 1 point on 2 functional system scales or 2 points on 1 functional system scale or increase in the EDSS score).

- Sustained accumulation of disability, defined as an increase from baseline of at least 1 EDSS point (or $\geq 1.5$ points if baseline EDSS score was 0 ) confirmed over 6 months.

Secondary outcome measure (24 months)

- Rate of relapse-free participants 
CARE-MS I (Continued)

- Change in EDSS

- Number of participants with new or enlarging T2-hyperintense lesions on magnetic resonance imaging

- Change in multiple sclerosis functional composite (MSFC)

- Freedom from clinical disease activity, defined as absence both of relapses and sustained accumulation of disability

- Freedom from MRI disease activity, defined as absence both of gadolinium-enhancing lesions and new or enlarging T2-hyperintense lesions

- Adverse events, actively searched by a monthly questionnaire follow-up of participants, complete blood counts, serum creatinine, urinalysis and microscopy monthly (every 3 months for participants in the interferon beta-1a group), and thyroid function tests every 3 months

- Raters completed a questionnaire assessing quality of the masking at each EDSS assessment

- All participants who received at least one dose of study drug were included in the efficacy and safety analyses according to treatment assignment ("modified ITT analysis")

- Funding: Genzyme. The study sponsor was involved in the design and undertaking of the trial, data analysis and interpretation, writing of the manuscript, and the decision to submit the manuscript for publication. Bayer Schering Pharma participated in the design and oversight of the trial. Clinical investigators collaborated with the sponsor to design and oversee the trial. The sponsor did the statistical analyses.

\section{Risk of bias}

\begin{tabular}{|c|c|c|}
\hline Bias & Authors' judgement & Support for judgement \\
\hline $\begin{array}{l}\text { Random sequence genera- } \\
\text { tion (selection bias) }\end{array}$ & Low risk & "We randomly allocated patients using an interactive voice response system" \\
\hline $\begin{array}{l}\text { Allocation concealment } \\
\text { (selection bias) }\end{array}$ & Low risk & Use of an interactive voice response system \\
\hline $\begin{array}{l}\text { Blinding of participants } \\
\text { and personnel (perfor- } \\
\text { mance bias) } \\
\text { All outcomes }\end{array}$ & High risk & $\begin{array}{l}\text { "Both study drugs have adverse effects that precluded masking of patients and } \\
\text { treating clinicians to treatment assignment, and subcutaneous interferon beta } \\
\text { 1a was available only in proprietary prefilled syringes that could not effectively } \\
\text { be duplicated for placebo" }\end{array}$ \\
\hline $\begin{array}{l}\text { Blinding of outcome EDSS } \\
\text { assessment } \\
\text { EDSS }\end{array}$ & High risk & $\begin{array}{l}\text { "In the absence of a masked rater, unmasked raters could submit EDSS assess- } \\
\text { ments" }\end{array}$ \\
\hline $\begin{array}{l}\text { Blinding of outcome as- } \\
\text { sessment (detection bias) } \\
\text { All outcomes, except } \\
\text { EDSS }\end{array}$ & Low risk & $\begin{array}{l}\text { "Stringent clinical and MRI rater masking, and adjudication of relapses by a } \\
\text { committee comprising six independent and masked neurologists" }\end{array}$ \\
\hline $\begin{array}{l}\text { Blinding of safety outcome } \\
\text { assessment }\end{array}$ & Low risk & $\begin{array}{l}\text { "Stringent clinical and MRI rater masking, and adjudication of relapses by a } \\
\text { committee comprising six independent and masked neurologists" }\end{array}$ \\
\hline $\begin{array}{l}\text { Incomplete outcome data } \\
\text { (attrition bias) } \\
\text { All outcomes }\end{array}$ & High risk & $\begin{array}{l}\text { Only participants who received at least one dose of study drugs were included } \\
\text { in the efficacy and safety analyses according to treatment assignment (modi- } \\
\text { fied ITT analysis) }\end{array}$ \\
\hline $\begin{array}{l}\text { Selective reporting (re- } \\
\text { porting bias) }\end{array}$ & Low risk & - \\
\hline Other bias & Low risk & \\
\hline
\end{tabular}




$\begin{array}{ll}\text { Methods } & \text { CARE-MS II (primary reference) } \\ \text { - Multicentric, phase III, randomised clinical trial } \\ \text { - } 194 \text { centres around the world } \\ \text { - } \mathrm{N}=798 \text { /available for analysis }=667 \\ \text { - Treatment duration: } 12 \text { months } \\ \text { - Follow-up: } 24 \text { months }\end{array}$

- 18 to 55 years of age

- Diagnosis of relapsing-remitting MS fulfilling the McDonald diagnostic criteria

- Disease duration of 10 years or less

- At least 2 relapses in the previous 2 years, with at least 1 in the previous year

- At least 1 relapse while on interferon beta or glatiramer acetate after at least 6 months of treatment

- Expanded Disability Status Scale (EDSS) scores of 5.0 or less

- Cranial and spinal MRI lesions fulfilling protocol-defined criteria (MRI scan demonstrating white matter lesions attributable to MS)

\section{Exclusion criteria:}

- Previous treatment with alemtuzumab

- Previous treatment with any investigational drug (i.e. a medication that is not approved at any dose or for any indication)

- Treatment with natalizumab, methotrexate, azathioprine or cyclosporine in the past 6 months

- Previous treatment with mitoxantrone, cyclophosphamide, cladribine, rituximab or any other immunosuppressive, or cytotoxic therapy (other than steroid treatment)

- Any progressive form of MS

- Any disability acquired from trauma or another illness that could interfere with evaluation of disability due to MS

- Major systemic disease that cannot be treated or adequately controlled by therapy

- Active infection or high risk of infection

- Autoimmune disorder (other than MS)

- Impaired hepatic or renal function

- History of malignancy, except basal skin cell carcinoma

- Medical, psychiatric, cognitive or other conditions that compromise the patient's ability to understand the patient information, to give informed consent, to comply with the trial protocol or to complete the study

- Known bleeding disorder

- Women of childbearing potential with a positive serum pregnancy test, pregnant or lactating

- Current participation in another clinical study or previous participation in CAMMS323 (NCT00530348)

- Previous hypersensitivity reaction to any immunoglobulin product

- Known allergy or intolerance to interferon beta, human albumin or mannitol

- Intolerance of pulsed corticosteroids, especially a history of steroid psychosis

- Inability to self administer subcutaneous (SC) injections or receive SC injections from caregiver

- Inability to undergo MRI with gadolinium administration

- Unwilling to use a reliable and acceptable contraceptive method throughout the study period (fertile participants only) 
- Alemtuzumab $12 \mathrm{mg}$ per day administered IV, once a day for 5 consecutive days at Month 0 and 12 mg per day administered through IV, once a day for 3 consecutive days at Month $12(n=436$, available for analysis $=426$ )

- Alemtuzumab $24 \mathrm{mg}$ per day administered IV, once a day for 5 consecutive days at Month 0 and $24 \mathrm{mg}$ per day administered IV, once a day for 3 consecutive days at Month $12(n=173$, available for analysis $=170)$

Alemtuzumab was administered in 2 annual cycles, once at the beginning of the study and again 1 year later

\section{Comparator}

- Interferon beta-1a (Rebif $\left.{ }^{\oplus}\right) 44 \mu \mathrm{g}$ administered 3 times weekly by subcutaneous self injections $(\mathrm{n}=$ 231 , available for analysis $=202$ )

Outcomes

\section{Primary outcome measure}

- Time to Sustained Accumulation of Disability (SAD) (time frame: 2 years)

- Relapse rate (time frame: 2 years). Relapse was defined as new or worsening symptoms with an objective changes in neurologic examination attributable to multiple sclerosis that lasted for at least 48 hours, that were present at normal body temperature and that were preceded by at least 30 days of clinical stability.

\section{Secondary outcome measures}

- Rate of participants who are relapse-free at year 2 (time frame: 2 years)

- Change from baseline in EDSS (Expanded Disability Status Scale) (time frame: 2 years)

- Acquisition of disability as measured by change from baseline in Multiple Sclerosis Functional Composite (MSFC) (time frame: 2 years)

- Number of participants with new or enlarging T2-hyperintense lesions in magnetic resonance

- Adverse effects

- Quality of life: assessed by Functional Assessment of Multiple Sclerosis (FAMS; scale 0 to 176 for total score); Medical Outcomes Study 36-Item Short-Form Survey (SF-36; scale 1 to 100; healthy population mean = 50; administered annually in the core study); and EuroQol in 5 Dimensions visual analogue scale (EQ-5D VAS; scale 0 to 100).

Co-primary endpoints were relapse rate and time to 6-month sustained accumulation of disability, comparing alemtuzumab $12 \mathrm{mg}$ and interferon beta-1a in all participants who received at least one dose of study drug.

- The $24 \mathrm{mg}$ per day group was discontinued to aid recruitment, but data were included for safety assessments. The decision to close recruitment into the alemtuzumab $24 \mathrm{mg}$ arm was made by the Neurology Steering Committee and Genzyme management without review of safety or efficacy data from this study.

- Raters completed a questionnaire assessing quality of the masking at each EDSS assessment.

- Funding: Genzyme (Sanofi) and Bayer - Schering Pharma.

\section{Risk of bias}

\begin{tabular}{lll}
\hline Bias & Authors' judgement & Support for judgement \\
\hline $\begin{array}{l}\text { Random sequence genera- } \\
\text { tion (selection bias) }\end{array}$ & Low risk & $\begin{array}{l}\text { "We randomly allocated patients with an interactive voice response system in a } \\
2: 2: 1 \text { scheme" }\end{array}$ \\
\hline $\begin{array}{l}\text { Allocation concealment } \\
\text { (selection bias) }\end{array}$ & Low risk & Use of an interactive voice response system \\
\hline \hline
\end{tabular}




\section{CARE-MS II (Continued)}

Blinding of participants and personnel (performance bias)

All outcomes
High risk

"Because both study drugs had adverse effects that precluded double-blinding, and interferon beta 1a proprietary syringes could not effectively be duplicated for placebo"

$\begin{array}{ll}\begin{array}{l}\text { Blinding of outcome EDSS High risk } \\ \text { assessment }\end{array} & \begin{array}{l}\text { "In the absence of a masked rater, unmasked raters could submit EDSS assess- } \\ \text { ments" }\end{array}\end{array}$
ments"

EDSS

Blinding of outcome as- Low risk sessment (detection bias)

All outcomes, except

EDSS

Blinding of safety outcome Low risk_ "Raters were masked to treatment-group assignment"
assessment

assessment

Incomplete outcome data Unclear risk

(attrition bias)

All outcomes

"Raters were masked to treatment-group assignment"

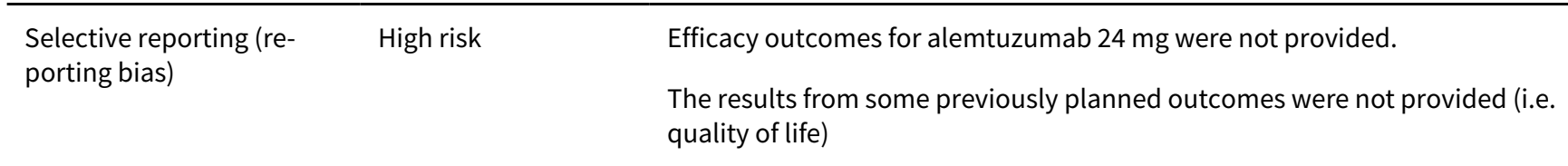

Other bias Low risk

EDSS: Expanded Disability Status Scale

ITT: intention-to treat

IV: intravenous

MRI: magnetic resonance imaging

MS: multiple sclerosis

SC: subcutaneous

VAS: visual analogue scale

DATA AND ANALYSES

Comparison 1. Alemtuzumab 12 mg versus interferon beta-1a

\begin{tabular}{lllll}
\hline Outcome or subgroup title & No. of studies & $\begin{array}{l}\text { No. of partici- } \\
\text { pants }\end{array}$ & Statistical method & Effect size \\
\hline 1 Relapse-free survival & 2 & Hazard Ratio (Fixed, 95\% Cl) & Subtotals only \\
\hline $\begin{array}{llll}1.1 \text { 24-month analysis } \\
\text { 2 Sustained disease progres- } \\
\text { sion-free survival }\end{array}$ & 2 & Hazard Ratio (Fixed, 95\% Cl) & $0.50[0.41,0.60]$ \\
\hline $\begin{array}{l}2.1 \text { 24-month analysis } \\
2.2 \text { 36-month analysis }\end{array}$ & 2 & Hazard Ratio (Fixed, 95\% Cl) & Subtotals only \\
\hline
\end{tabular}




\begin{tabular}{|c|c|c|c|c|}
\hline Outcome or subgroup title & No. of studies & $\begin{array}{l}\text { No. of partici- } \\
\text { pants }\end{array}$ & Statistical method & Effect size \\
\hline $\begin{array}{l}3 \text { Number of participants with } \\
\text { at least one adverse event }\end{array}$ & 3 & & Risk Ratio (M-H, Fixed, 95\% Cl) & Subtotals only \\
\hline 3.1 24-month analysis & 2 & 1248 & Risk Ratio (M-H, Fixed, 95\% Cl) & $1.04[1.01,1.06]$ \\
\hline 3.2 36-month analysis & 1 & 224 & Risk Ratio (M-H, Fixed, 95\% Cl) & $1.0[0.98,1.02]$ \\
\hline 4 Change in EDSS score & 3 & & $\begin{array}{l}\text { Mean Difference (IV, Random, 95\% } \\
\mathrm{CI})\end{array}$ & Subtotals only \\
\hline 4.124-month analysis & 2 & 1199 & $\begin{array}{l}\text { Mean Difference (IV, Random, 95\% } \\
\mathrm{CI})\end{array}$ & $-0.20[-0.60,0.20]$ \\
\hline 4.2 36-month analysis & 1 & 223 & $\begin{array}{l}\text { Mean Difference (IV, Random, 95\% } \\
\mathrm{CI})\end{array}$ & $-0.7[-1.04,-0.36]$ \\
\hline $\begin{array}{l}5 \text { Number of participants with } \\
\text { new or enlarging T2-hyperin- } \\
\text { tense lesions }\end{array}$ & 2 & 1238 & Risk Ratio (M-H, Random, 95\% Cl) & $0.74[0.59,0.91]$ \\
\hline 6 Number of dropouts & 3 & & Risk Ratio (M-H, Fixed, 95\% Cl) & Subtotals only \\
\hline 6.124-months analysis & 2 & 1248 & Risk Ratio (M-H, Fixed, 95\% Cl) & $0.31[0.23,0.41]$ \\
\hline 6.2 36-months analysis & 1 & 224 & Risk Ratio (M-H, Fixed, 95\% Cl) & $0.81[0.57,1.14]$ \\
\hline
\end{tabular}

Analysis 1.1. Comparison 1 Alemtuzumab 12 mg versus interferon beta-1a, Outcome 1 Relapse-free survival.

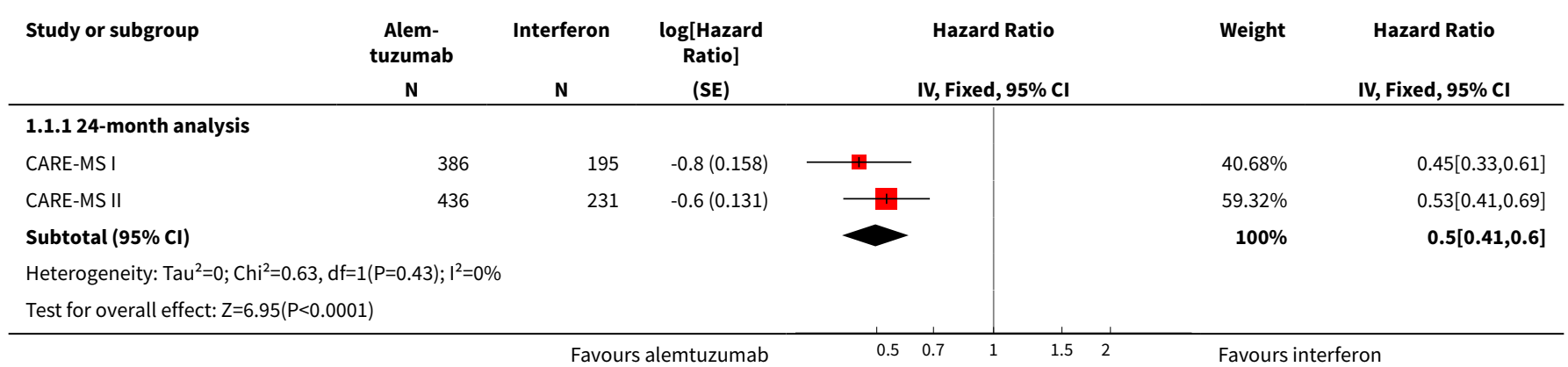

Analysis 1.2. Comparison 1 Alemtuzumab $12 \mathrm{mg}$ versus interferon beta-1a, Outcome 2 Sustained disease progression-free survival.

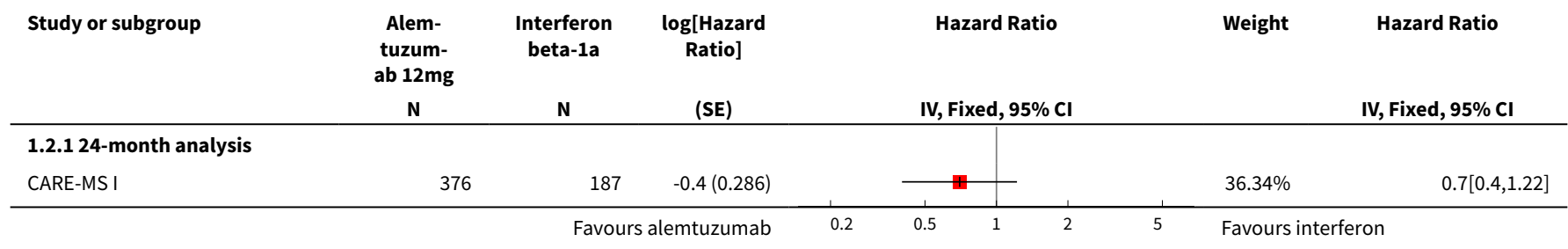




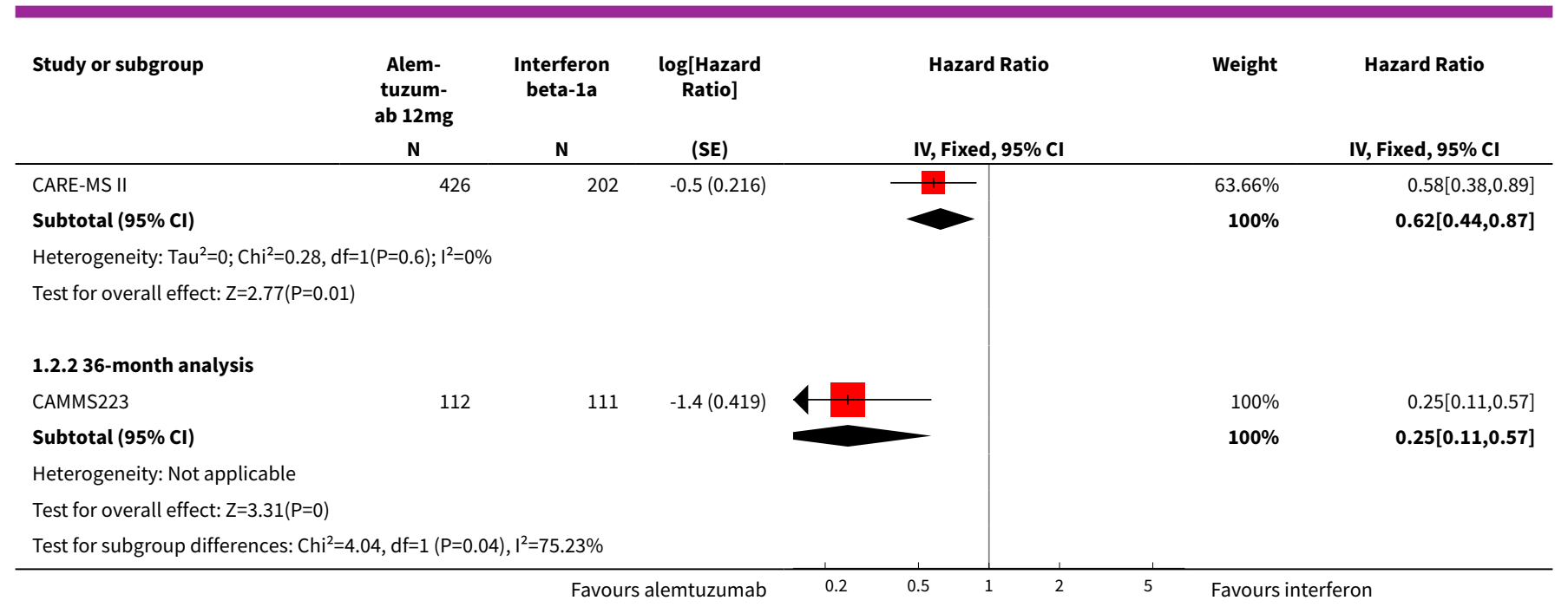

Analysis 1.3. Comparison 1 Alemtuzumab 12 mg versus interferon beta-1a, Outcome 3 Number of participants with at least one adverse event.

\begin{tabular}{|c|c|c|c|c|c|}
\hline Study or subgroup & $\begin{array}{c}\text { Alemtuzum- } \\
\text { ab } 12 \mathrm{mg} \\
\mathrm{n} / \mathrm{N} \\
\end{array}$ & $\begin{array}{c}\text { Interfer- } \\
\text { on beta-1a } \\
n / N \\
\end{array}$ & M-H, Fixed, 95\% CI & Weight & $\begin{array}{c}\text { Risk Ratio } \\
\text { M-H, Fixed, 95\% Cl }\end{array}$ \\
\hline \multicolumn{3}{|c|}{ 1.3.1 24-month analysis } & & & \\
\hline CARE-MS I & $371 / 386$ & $180 / 195$ & 要 & $45.4 \%$ & $1.04[1,1.09]$ \\
\hline CARE-MS II & $429 / 436$ & $220 / 231$ & & $54.6 \%$ & $1.03[1,1.07]$ \\
\hline Subtotal $(95 \% \mathrm{Cl})$ & 822 & 426 & & $100 \%$ & $1.04[1.01,1.06]$ \\
\hline \multicolumn{6}{|c|}{ Heterogeneity: $\operatorname{Tau}^{2}=0 ; \mathrm{Chi}^{2}=0.08, \mathrm{df}=1(\mathrm{P}=0.77) ; \mathrm{I}^{2}=0 \%$} \\
\hline \multicolumn{6}{|c|}{ Test for overall effect: $Z=2.65(P=0.01)$} \\
\hline \multicolumn{6}{|c|}{ 1.3.2 36-month analysis } \\
\hline CAMMS223 & $113 / 113$ & $111 / 111$ & & $100 \%$ & $1[0.98,1.02]$ \\
\hline Subtotal $(95 \% \mathrm{CI})$ & 113 & 111 & & $100 \%$ & $1[0.98,1.02]$ \\
\hline \multicolumn{6}{|c|}{ Heterogeneity: Not applicable } \\
\hline \multicolumn{6}{|c|}{ Test for overall effect: Not applicable } \\
\hline Test for subgroup dif & $95, d f=1(P=0.03)$, & $9.79 \%$ & & & \\
\hline
\end{tabular}

Analysis 1.4. Comparison 1 Alemtuzumab $12 \mathrm{mg}$ versus interferon beta-1a, Outcome 4 Change in EDSS score.

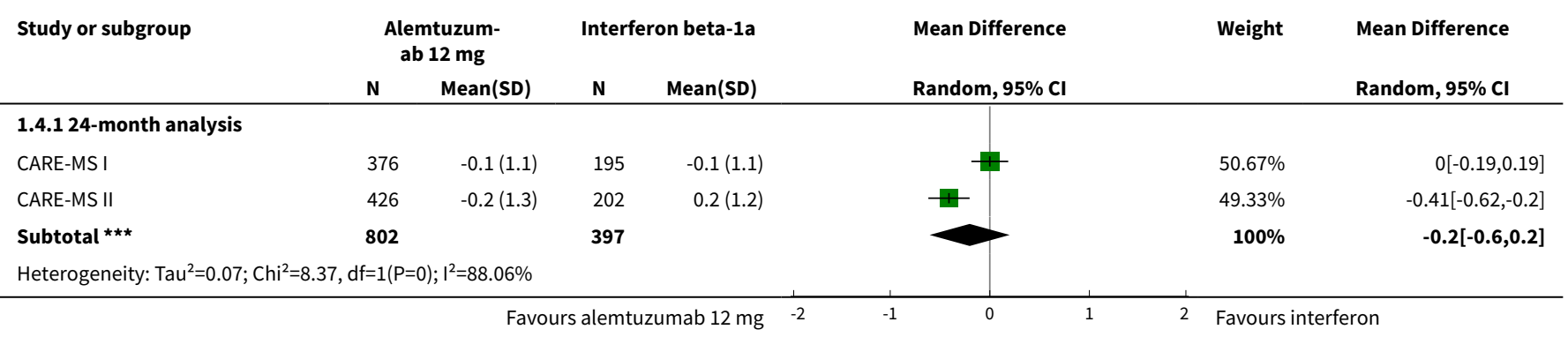




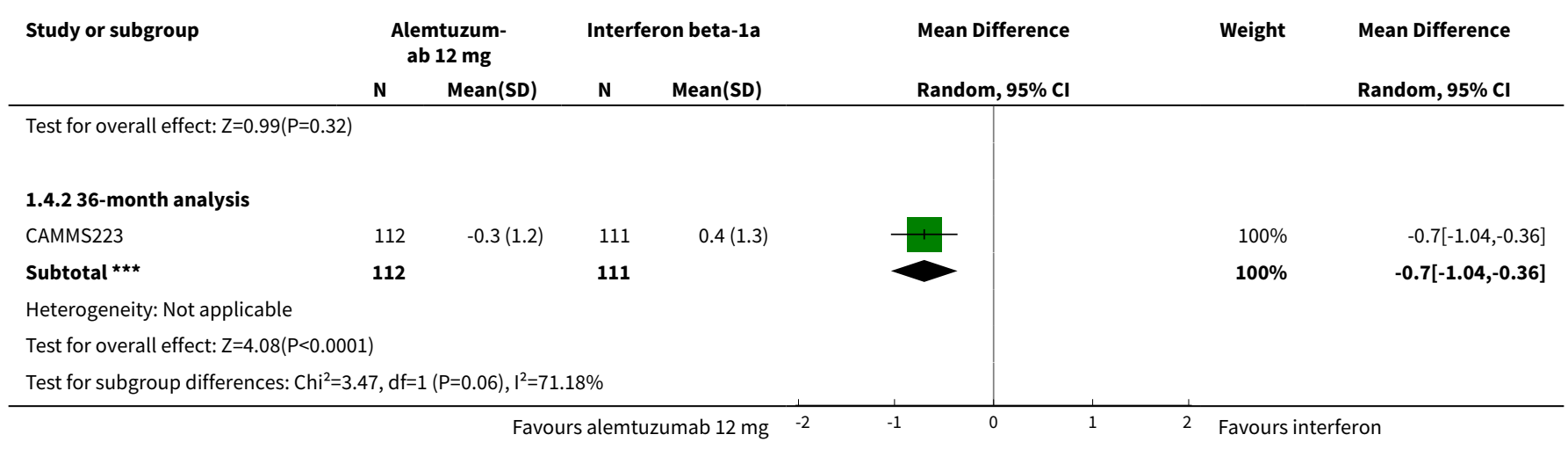

Analysis 1.5. Comparison 1 Alemtuzumab $12 \mathrm{mg}$ versus interferon beta-1a, Outcome 5 Number of participants with new or enlarging T2-hyperintense lesions.

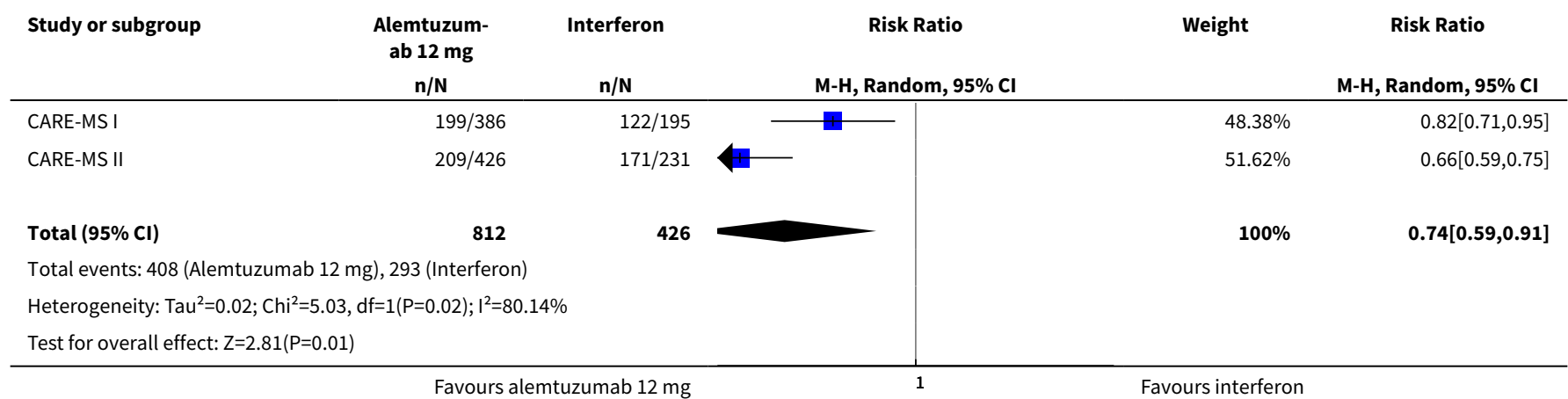

Analysis 1.6. Comparison 1 Alemtuzumab 12 mg versus interferon beta-1a, Outcome 6 Number of dropouts.

\begin{tabular}{cccc} 
Study or subgroup & $\begin{array}{c}\text { Alemtuzum- } \\
\text { ab } 12 \mathrm{mg} \\
\mathrm{n} / \mathrm{N}\end{array}$ & $\begin{array}{c}\text { Interfer- } \\
\text { on beta-1a } \\
\mathrm{n} / \mathrm{N}\end{array}$ & Risk Ratio \\
& $\mathrm{M}-\mathrm{H}$, Fixed, $95 \% \mathrm{Cl}$ & Weight \\
\hline
\end{tabular}

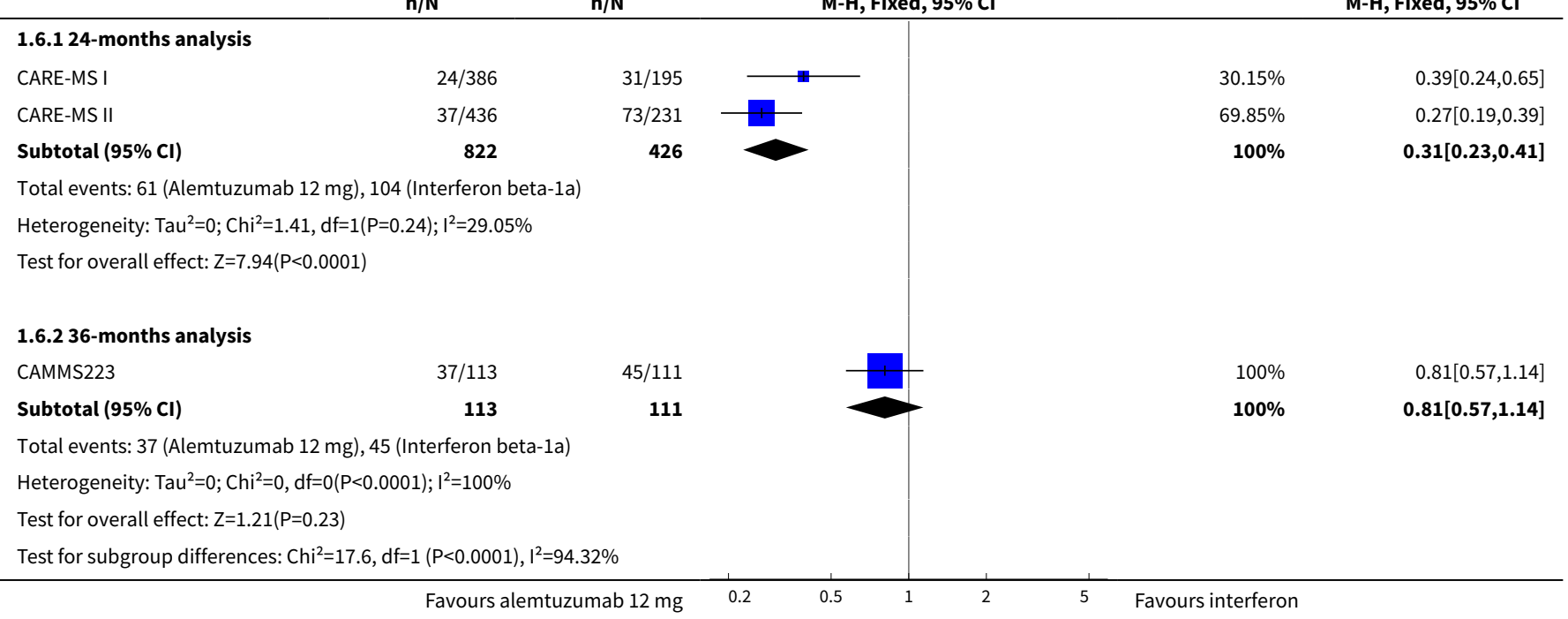




\section{A P PE N D I CES}

\section{Appendix 1. Keywords for searching the Cochrane Multiple Sclerosis and Rare Diseases of the Central Nervous System Group Trials Register}

\{alemtuzumab\} OR \{Campath 1G\} OR \{Campath-1G\} OR \{Campath-1-G\} OR \{Campath 1M OR \{Campath-1M OR \{MabCampath $\}$ OR \{Schering brand of alemtuzumab\} OR \{Campath\} OR \{Berlex brand of alemtuzumab\} OR \{Campath $1 \mathrm{H}\}$ OR \{monoclonal antibody Campath-1H\} OR \{Campath-1H\} OR \{monoclonal antibody $\left.{ }^{\star}\right\}$ OR \{Antibodies, Monoclonal\} OR \{lemtrada\}

\section{WHAT'S NEW}

\begin{tabular}{lll}
\hline Date & Event & Description \\
\hline 30 April 2015 & Amended & The author team has been amended. \\
\hline
\end{tabular}

\section{CONTRIBUTIONSOF AUTHORS}

- RR was the contact person with the editorial base who co-ordinated the contributions from co-authors and was responsible for the final draft of the review.

- RR, GJMP and MRT worked on study selection, data extraction, 'Risk of bias' assessment and GRADE.

- RR and GJMP performed the results analyses.

- RR, GJMP and MRT wrote the discussion and conclusions.

- RR responded to the clinical comments of the referees.

- RR, GJMP and MRT answered the methodological and statistical questions of the referees.

- RR, GJMP and MRT will be in charge of further updating.

\section{DECLARATIONSOF INTEREST}

RR: none

GJMP: none

MRT: none

\section{SOURCES OF SUPPORT}

\section{Internal sources}

- Brazilian Cochrane Centre, Brazil.

\section{External sources}

- No sources of support supplied

\section{DIFFERENCES BETWEEN PROTOCOL AND REVIEW}

- One of the co-authors of the protocol, for unforeseen reasons, could no longer collaborate on the review and asked to be excluded from authoring.

- We planned the following subgroup analyses at the protocol stage but did not perform them due to lack of sufficient data: different doses and regimens, disease type (relapsing-remitting, primary-progressive, secondary-progressive or progressive-relapsing), disability at baseline (EDSS scores $\leq 5.0$ or $\geq 5.5$ ).

- We did not plan the subgroup analysis taking into account previous treatment (naive versus pre-treated patients) at the protocol stage but as it seemed to be clinically relevant, we performed it when there were sufficient data.

- In the protocol, we proposed to assess 'number of participants without relapse' and 'number of progression-free participants' as primary outcomes. However, we found available data only for 'relapse-free survival' and 'sustained disease progression-free survival'. We decided to use both of these measures in the final review, since they are the opposite of the same measurement and this change would not influence the effect of the intervention nor its interpretation. 
- In the protocol, we proposed to assess the 'Changes in the number of MRI T2- and T1-weighted lesions after treatment'. However, we discussed among the review authors and peer reviewers whether 'Patients with new or enlarging T2-hyperintense lesions' could more relevant for decision-making, since it comprises the total area of all MS lesions. Moreover, since this is a dichotomous measure, it could be easier for physicians and consumers to interpret. We considered this outcome relevant enough (despite the fact that it is a secondary outcome) to warrant a change in its presentation regardless of the tool/measurement used to assess it. Therefore we decided to change the way it was measured, leading to the presentation of the existing results.

- We planned the following outcomes for the 'Summary of findings' table at the protocol stage but we did not include them due to lack of data: one-point EDSS score increase confirmed at three months' follow-up and quality of life. We included the outcome dropout rate in the 'Summary of findings' table.

- In the protocol we did not pre-define the use of the hazard ratio to estimate the effect size of time-to-event outcomes. We added this information in the final version of the review because we used this measure for the outcomes relapse-free survival and sustained disease progression.

\section{N DEX TERMS}

\section{Medical Subject Headings (MeSH)}

Alemtuzumab; Antibodies, Monoclonal, Humanized [*therapeutic use]; Disease-Free Survival; Interferon beta-1a [therapeutic use]; Multiple Sclerosis, Relapsing-Remitting [ ${ }^{\star}$ drug therapy]; Randomized Controlled Trials as Topic

\section{MeSH check words}

Adult; Humans 